\title{
Optimal family taxation and income inequality
}

\author{
Patricia Apps ${ }^{1,2}$ - Ray Rees ${ }^{1,3,4}$
}

\begin{abstract}
This paper presents the properties of optimal piecewise linear income tax systems for families, based on joint and individual incomes. It models the interaction between the wage rates of mothers as "second earners" and variation in child care prices and productivities as determinants of heterogeneity in second earner labour supply. We find that individual taxation welfare dominates joint taxation on grounds of both efficiency and equity. Heterogeneous labour supplies, the positive relationship between household wages and child care quality, and the sharp rise in wage rates in the top percentiles of the primary wage distribution account for this result. In addition to reducing the intra-household net-of-tax wage gap, individual taxation removes the opportunity for tax avoidance that income-splitting makes available to high-wage primary earners, leading to a much fairer distribution of the tax burden.
\end{abstract}

Keywords Optimal taxation · Piecewise linear - Labour supply · Child care · Inequality

JEL Classification D31 $\cdot \mathrm{H} 21 \cdot \mathrm{H} 24 \cdot \mathrm{H} 31 \cdot \mathrm{J} 22$

$凶$ Patricia Apps

patricia.apps@sydney.edu.au

1 The University of Sydney Law School, The University of Sydney, Sydney, NSW 2000, Australia

2 IZA, Bonn, Germany

3 LMU Munich, Munich, Germany

4 CESifo, Munich, Germany 


\section{Introduction}

There is a long history of criticism of the system of joint taxation, commonly known as joint filing or income-splitting, by tax economists. ${ }^{1}$ The early critique was based on a straightforward, and still valid, efficiency argument. Under a progressive rate scale, joint taxation equalises the marginal tax rates on the incomes of a two-earner couple, whereas under individual taxation the second earner on a lower wage, typically the female partner, is likely to face a lower marginal tax rate than the primary earner, to an extent dependent on the difference in the partners' incomes, the widths of the tax brackets and the progressivity of the marginal rate scales. The then available empirical evidence $^{2}$ suggested that female workers had significantly higher compensated labour supply elasticities than did prime-age male workers. So, a straightforward application of the Ramsey Principle argues for individual income as the tax base with a lower marginal tax rate on female workers at any given income level. ${ }^{3}$ Now, at least 5 decades after increased levels of female labour force participation made the issue of the taxation of couples a central one in tax policy, income-splitting still seems to be firmly enshrined in the personal income tax systems of two of the world's largest economies, Germany and the USA, with no obvious indications of the likelihood of change. ${ }^{4}$

A strong intuition in support of joint taxation is that a household's standard of living is strictly increasing with its total income from market labour supply. This suggests that a move from joint to individual income as the tax base could have adverse equity effects because, in a tax system with marginal tax rates increasing in income, such a change can result in two households with the same aggregate income paying different amounts of tax, or even one with a higher joint income paying less tax, depending on the relative incomes of the primary and second earner. ${ }^{5}$ This would seem to violate the principles of both vertical and horizontal equity and could imply that a tax reform replacing joint with individual taxation would reduce social welfare, because adverse equity effects could outweigh the gain in economic efficiency. ${ }^{6}$

\footnotetext{
1 See, for example, Rosen (1977) and Boskin and Sheshinski (1983).

2 See Heckman and Killingsworth (1986) for a survey of the literature of that period. More recent empirical studies confirm these earlier results, see, for example, LaLumia (2008), McClelland et al. (2014) and Steiner and Wrohlich $(2004,2008)$.

3 Individual taxation, by imposing a lower tax rate on the second income, lowers the net-of-tax gender pay gap, and therefore the gender gap in "outside opportunities". Since Alesina et al. (2011) a tax system with a lower rate on the second income has been referred to as "gender-based taxation".

4 Forms of income-splitting vary across countries. The US and Germany are two of the few countries with full income splitting. Others have partial income-splitting or quasi-joint taxation systems due to the withdrawal of family payments or tax credits on joint income. For a comparative analysis of the Australian, German, UK and US systems, see Apps and Rees (2009, Ch. 6).

5 We define primary and second earners simply in terms of who has the higher earned income, rather than in terms of gender. The second earner typically also has the lower wage rate, though this need not invariably be the case. However, the average wage rate of second earners is certainly below that of primary earners. In OECD countries, typically around $80 \%$ of second earners are female. For an informative study of the changing gender composition of second earners based on panel data derived from US federal income tax returns, see McClelland et al. (2014).

6 See Apps and Rees (1999) for a rigorous discussion of this possibility. It can certainly arise in the model of Boskin and Sheshinski (1983) if the difference in compensated elasticities of male and female spouses
} 
However, it is not just money income that determines a household's real living standard. We also have to take into account the value of household goods and services produced and consumed within the household. Where these are produced primarily by the (potential) second earner using time that could alternatively be spent earning market income, this untaxed contribution to the household's living standard may actually vary inversely with its total money income. It is certainly not wildly improbable that the total value of the second earner's household production could be at least comparable to her net-of-tax market income if she worked full time, especially if it involves a great deal of child care.

In general terms, the central issue is the extent of the gains in equity and efficiency in moving from joint to individual taxation in an economy where domestic production is a significant form of time use ${ }^{7}$ and households differ widely in their second earner labour supplies and therefore values of domestic output.

In this paper, we explore this issue in depth and show that in fact there is a further, so far unappreciated strand in the equity argument. This goes beyond the recognition of the real patterns of time use within households and second earner labour supply heterogeneity and has become of increasing significance in the last few decades. This has been a period characterised by increasing wage and income inequality ${ }^{8}$ and falling top tax rates. ${ }^{9}$ By comparing two optimal piecewise linear tax systems for a given population of heterogeneous households, the first with joint, the second with individual incomes as the tax base, we show in this paper that incomesplitting imposes a severe constraint on the extent to which income can be redistributed from households with very high standards of living to those that are in the low to middle ranges of the distribution of well-being. Income-splitting could in fact be viewed as a means of tax avoidance: having the second earner substitute household for market work is a perfectly legal means by which a high-income primary earner can significantly reduce his tax bill. We show here that ending the advantage of income-splitting to high-income households and decoupling the labour supply elasticities of primary and second earners leads to a more progressive tax system in which equity gains in fact reinforce the efficiency gains of the move to individual taxation.

\footnotetext{
Footnote 6 continued

is sufficiently small. They presented a numerical model calibrated on the then existing empirical work on labour supply elasticities and obtained the result that the tax rate on women should be significantlypossibly as much as $50 \%$ - below that of their spouses in an optimal linear tax system. Their underlying household model was one in which household utility depended on aggregate consumption and male and female labour supplies. They also assumed that the female wage was a monotonic function of the male wage. The contribution of this paper is to base the analysis on a far more richly specified household model and to analyse optimal piecewise linear taxation, thus allowing for progressivity in marginal tax rates.

7 For earlier analyses of income taxation with household production see Alesina et al. (2011), Apps and Rees (1988, 1999), Boskin (1975) and Sandmo (1990).

8 For empirical work on this, see Atkinson (2015), Atkinson et al. (2011) and Piketty and Saez (2003).

9 This very important development in the tax structures of high-income countries is thoroughly documented in Peter et al. (2010).
} 
This analysis of taxing couples under piecewise linear tax systems is new to the tax theory literature ${ }^{10}$ which up until now has focused either on linear taxation, ${ }^{11}$ tax reform, ${ }^{12}$ or on nonlinear taxation ${ }^{13}$ in the tradition of Mirrlees (1971). One reason for our approach here is that in reality almost all tax systems are piecewise linear, and the conditions that characterise the optimal tax rates, as well as their intuitive interpretations, are to a large extent different from those derived from the mechanism design approach, where incentive compatibility constraints and the implementation of a separating equilibrium across wage types are central to the analysis. ${ }^{14}$ A piecewise linear tax system involves pooling of wage types within each of a relatively small number of subsets of the taxed population.

Our approach also allows us to use a generalised structural model of the household, set out in the next section, in which the specification of a household's type can be far richer than that used in optimal nonlinear taxation models, where the restrictions on the number of dimensions of private information that can be handled severely limits the type specification and general structure of the household model. ${ }^{15}$

The paper is set out as follows. In the next section, we present the structural household model that provides the analytical basis for the indirect utility and labour supply functions ${ }^{16}$ used in the tax analysis, and for the later numerical simulations. In Sect. 3 , we define the tax systems and carry out the optimal tax analysis for joint and individual taxation, respectively. In Sect. 4, we present the results of the numerical analysis of the optimal tax systems for alternative empirical specifications of the household model, and we show that individual taxation is consistently welfare superior under plausible assumptions on productivities and prices that can generate the data on household labour supplies. Section 5 concludes.

\section{The household model}

We present a model of the two-earner household in which a household's type depends not only on the wage rates of the two earners but also on the price and quality it faces

\footnotetext{
10 The literature on optimal piecewise linear income taxation for single person households is also not large. See Sheshinski (1989), Dahlby (1998, 2008), Slemrod et al. (1994), Apps et al. (2014), and Andrienko et al. (2016).

11 As in the seminal paper by Boskin and Sheshinski (1983).

12 See Apps and Rees (1999).

13 See Apps and Rees (2009, Ch. 8) for a literature survey.

14 Almost all discussions of tax policy issues based on this approach, for example that surrounding the well-known Atkinson-Stiglitz Theorem, revolve around the extent to which policy measures do or do not relax the incentive compatibility constraint. There is absolutely no reason to believe that real tax systems satisfy an incentive compatibility constraint.

15 Thus, Apps and Rees (2009, Ch. 8), Brett (2007) and Schroyen (2003) assume just two wage types for each of primary and second earners, while the formidably technical paper by Kleven et al. (2009) generalises this to a continuum of primary earners but assumes that second earners either work full time in the market, all for the same wage, or full time in the household. These rather counterfactual assumptions are made in order to have tractable models with which to characterise optimal nonlinear tax functions for two-earner households.

16 Detailed derivations of these are given in Appendix A.
} 
for the bought-in input into household production-represented canonically by child care-and by its own productivity in child care, as determined by its human and physical capital. A large and growing number of empirical studies find that child outcomes improve with maternal human capital and that parental investment in child care and education rises with family resources. ${ }^{17}$ We interpret this literature as implying that the productivity of time spent in child care, in terms of the resulting quality of the child's human capital, can be modelled as increasing in the mother's wage. Recent studies have argued that in consequence the quality of investment in child development must be perceived as an additional dimension of across-household inequality. ${ }^{18}$

This is therefore very relevant for the appraisal of alternative tax systems in terms of their implications for distributional equity, the main subject of this paper. ${ }^{19}$ The numerical simulations of our Model 1 presented in Sect. 4 constitute, we believe, the first attempt to integrate this dimension into an analysis of optimal family taxation. The presentation of the theoretical results of the optimal tax analysis, in terms of the standard "sufficient statistics", ${ }^{20}$ conceals this dimension of the underlying structural model, and this makes it all the more important to incorporate it into the numerical analysis based on this model. Model 2 of Sect. 4 corresponds more closely to the standard labour supply model, and, in clear contrast to Model 1, assumes that the quality and price of child care are constant across households. This means that in the analysis of household taxation this model cannot deal with the implications of across-household variation in these variables in an empirically plausible way. ${ }^{21}$

Households are assumed to consist of couples with the same number of children, normalised at one. ${ }^{22}$ The primary earner divides his time between market work and leisure, while the second earner allocates her time to market work and to the household production of child care. $^{23}$

The productivity of the second earner's time input to child care is assumed to vary randomly across households, with a distribution whose mean value shifts upward with her wage. This shift reflects differences in human and physical capital. There is in addition a bought-in child care time input. The price of this input at any given quality

17 See, for example, Almond and Currie (2011), Björklund et al. (2006), Black et al. (2005), Black and Devereux (2011), Currie and Moretti (2003), Holmlund et al. (2001), Dahl and Lochner (2012), Löken et al. (2012), Lundborg et al. (2014) and Milligan and Stabile (2011).

18 See in particular Lundberg et al. (2016).

19 The implications for efficiency are well known.

20 See Chetty (2009).

21 Variation in quality cannot, for example, be taken into account in the Boskin and Sheshinski (1983) analysis, because of the assumption there that time is divided between work and leisure, and a unit of leisure time has the same productivity or marginal utility across all households.

22 In that case, we are ruling out variations in the number of children as being the main determinant of heterogeneity in second earner labour supply. This is consistent with the empirical evidence: see Apps and Rees (2009). It also implies that we are excluding from the tax analysis single person households and childless couples. This is essentially on the grounds of simplicity and is the subject of further work. For the time being, note that all but a small proportion of the entire optimal tax literature is concerned with singles.

23 Nothing would be gained by having both parents consume leisure and contribute to household production. Although that would be more realistic, we think the assumption made here captures the salient aspects of reality - the differing margins of substitution facing primary and second earners — while keeping the model simple. 
varies randomly across households, while increases in quality shift the mean of this distribution of prices upward. The household chooses its optimal quality level given the market-determined relation between quality and price that it faces. The realisations of the random variables determining productivities and prices are known when decisions are taken and so there is no uncertainty, they are there to generate across household heterogeneity.

The motivation for this emphasis on variation in the price of child care of a given quality is based upon everyday observation. In media articles and social surveys, parents report that the main obstacle to second earner labour supply is the problem of finding child care of an acceptable quality and price. Costs of bought-in child care vary not only with its quality or type, or mix of types, ${ }^{24}$ but also with location, age of children and other household characteristics. Moreover, households commonly report that, net of taxes and other costs of going out to work, child care expenditure can swallow a large part, if not all or even more than all, of the second earner's income. ${ }^{25}$

An obvious motivation for working even when there is a negative net return is that the second earner is investing in maintaining her work-related human capital over the period in which the demand for child care is strongest, so as to be in a better labour market situation when that demand falls substantially. This cannot be drawn upon formally, however, in a static model of the type developed here. ${ }^{26}$ An alternative is that the productivity/quality of bought-in care is sufficiently high that its contribution to child development can offset the negative return. There is no obvious reason for the costs of bought-in contributions to the development of the child's human capital to be constrained by the income of only the second earner.

We model these observations in the following way. There is a composite market consumption good, $x$, individuals face given gross wage rates $w$, representing their productivities in a linear aggregate production technology that produces $x$, and have earnings $y=w l$ from their labour supply $l$. In addition to the market consumption good, household utility depends on child care output, $z$, which is produced using the second earner's time input, $c$, and a bought-in child care time input, $b$, according to a standard linear homogeneous, strictly quasiconcave and increasing production function

$$
z=z(k c, q b)
$$

where $k$ and $q$ are strictly positive measures of the productivity/quality in child care of one unit of $c$ and $b$, respectively. We assume that $k$ is defined by $k=k\left(w_{2}\right)+\tilde{\kappa}$ with $k^{\prime}\left(w_{2}\right)>0$ and $\tilde{\kappa} \in\left[\kappa_{0}, \kappa_{1}\right] \subset \mathbf{R}$ a zero-mean random variable. The price of bought-

\footnotetext{
24 Ranging from grandparents and other family members, neighbours or an au pair, through day-care centres and private child-minders, to highly trained tutors.

25 Variation in the price of bought-in child care may also be due to government taxes or subsidies for child care, in addition to stochastic variation in the market price. These may be set by agencies other than the tax authority. An extension of our approach in this paper could of course be used to analyse optimal policies towards child care provision. Apps and Rees (2004) analyse the effects of child care subsidies on household labour supplies and fertility choices.

26 We need a life cycle-based model of optimal taxation which will show how taxes vary as a household moves over successive phases in its "family life cycle", see Apps and Rees (2009, Ch. 5).
} 
in care of a given quality $q$ is given by $p=p(q)+\tilde{\varepsilon} \geq 0$, where $\tilde{\varepsilon} \in\left[\varepsilon_{0}, \varepsilon_{1}\right] \subset \mathbf{R}$ is another zero-mean random variable and $p^{\prime}(q)>0, p^{\prime \prime}(q) \geq 0$.

The "type" of a household depends on its wage pair $\left(w_{1}, w_{2}\right)$, and its realisations of home child care productivity $\tilde{\kappa}$ and price of bought-in child care $\tilde{\varepsilon}$. A household's type is therefore defined by the 4-tuple $\left(w_{1}, w_{2}, \tilde{\kappa}, \tilde{\varepsilon}\right)$, and we let the index $h \in \mathcal{H} \subset \mathbf{R}^{4}$ correspond to a particular value of this, with $\mathcal{H}$ the set of 4 tuples. Thus, in this model, at any given primary earner wage rate $w_{1 h}$, across-household heterogeneity is driven by variations in $p_{h}, w_{2 h}$ and $k_{h}$.

The household utility function is given by

$$
u_{h}=x_{h}-\hat{u}_{1}\left(l_{1 h}\right)+\hat{u}_{2}\left(z\left(k_{h} c_{h}, q_{h} b_{h}\right)\right) \quad h \in \mathcal{H}
$$

The $\hat{u}_{1}(\cdot)$ function is a strictly increasing and strictly convex function of the primary earner's labour supply $l_{1 h}$, representing the standard trade-off between work and leisure, while $\hat{u}_{2}(\cdot)$ is a strictly increasing and strictly concave function of $z_{h}$ and therefore of $c_{h}, b_{h}$.

For the second earner, the time spent in market work and child care must sum to the total time endowment, ${ }^{27}$ normalised at 1 , and so we have

$$
c_{h}+l_{2 h}=1 \quad h \in \mathcal{H}
$$

where $l_{2 h}$ is second earner market labour supply.

There is, however, a further important time constraint: although second earner time and bought-in child care may not be perfect substitutes as inputs in producing child care, realistically it is the case that every hour the second earner spends at work requires an hour of child care ${ }^{28}$ in which case

$$
b_{h}=l_{2 h} \quad \forall h \in \mathcal{H}
$$

In the absence of taxation, the household budget constraint is then

$$
x_{h} \leq w_{1 h} l_{1 h}+\left[w_{2 h}-p_{h}\left(q_{h}\right)\right] l_{2 h} \quad h \in \mathcal{H}
$$

As this budget constraint shows, we can view the price of child care as in effect a tax on the second earner's market labour supply and, at a given choice of quality, variations in $w_{2 h}$ and $p_{h}$ have equal but opposite effects. It should be noted that empirically the possible range of variation of $w_{2 h}$-from minimum wage to something typically below the primary earner's wage-is much narrower than that of $p_{h}$, which can range from zero to something greater than the primary wage. For that reason, in the numerical analysis in Sect. 4, we consider the effect of variations in $p_{h}$ rather than in $w_{2 h}$.

\footnotetext{
27 For the primary earner, it is sufficient to assume that the convexity of $\hat{u}_{1}(\cdot)$ is such that $l_{1 h}<1$ at all equilibria.

28 Vidar Christiansen has suggested to us that this should perhaps be a weak inequality — a household might well buy inputs into child human capital formation, math tutorials for example, that are supplied outside of parental working time. While we fully agree with the realism of this point, we remain here with the simpler case, implicitly assuming that this constraint is binding. Even more realistically, we should recognise that there are different types of bought-in market inputs.
} 


\subsection{Household equilibrium}

Using the above time constraints, the household's problem can be written as

$$
\max _{x_{h}, l_{i h}, q_{h}} u_{h}=x_{h}-\hat{u}_{1}\left(l_{1 h}\right)+\hat{u}_{2}\left(z\left(k_{h}\left(1-l_{2 h}\right), q_{h} l_{2 h}\right)\right) \quad h \in \mathcal{H}
$$

subject to the budget constraint in (5), and $k_{h}=k\left(w_{2 h}\right)+\kappa_{h}>0, p_{h}=p\left(q_{h}\right)+\varepsilon_{h}>$ 0 , with $\kappa_{h}$ and $\varepsilon_{h}$ the household's realisations of $\tilde{\kappa}$ and $\tilde{\varepsilon}$, respectively.

The first-order condition ${ }^{29}$ determining $l_{2 h}^{*}$ is rather more interesting than the conventional expressions determining second earner labour supply. We can write this as

$$
\mathrm{MVP}_{\mathrm{c}}-\mathrm{MVP}_{\mathrm{b}}=w_{2 h}-p_{h}=w_{2 h}-\left(p\left(q_{h}^{*}\right)+\varepsilon_{h}\right)
$$

where $\mathrm{MVP}_{\mathrm{b}}, \mathrm{MVP}_{\mathrm{c}}$ denote the household marginal value products of bought-in and domestic child care, respectively, in terms of the numeraire consumption, at the household equilibrium. The right hand side of this equation is the household's net marginal return to a unit of market labour supply $l_{2 h}$, and therefore, the marginal opportunity cost of domestic child care, given the bought-in child care quality $q_{h}^{*}$. The left hand side represents the difference in marginal value products of domestic and bought-in care, respectively. If we ignore bought-in care, the condition would be the standard $\mathrm{MVP}_{\mathrm{c}}=w_{2 h}$. However, since an hour of $l_{2 h}$ requires an hour of $b_{h}$, the return to market labour supply net of the cost of bought-in care will be equated to the difference between marginal value products of the two types of child care.

Given the main concern of this paper, the welfare comparison of alternative tax systems, we interpret the results of the comparative statics analysis of this model ${ }^{30}$ not as showing how a given "representative household" would respond to a change in the exogenous variables, but rather as suggesting how second earner labour supply and child care quality vary across households as we move through the joint distribution of bought-in child care prices, wage rates and child care productivities. These results confirm that we would not expect a clear, positive relationship between household income, on the one hand, and the achieved utility level of the household, on the other. This is because the variations in child care prices and productivities generate wide variations in second earner labour supply at any given wage pair, with reductions in this labour supply being associated with increases in the value of the output of child care that may at least compensate for the loss of market income. These comparative statics effects are brought out clearly in the numerical analysis of Sect. 4 below. First we turn to the optimal tax analysis.

\section{Tax analysis}

As Chetty (2009) argues, whatever might be the underlying structural household model, an optimal tax system can at a general level be characterised by a small number

\footnotetext{
29 See Appendix A for the full set of first-order conditions.

30 Given in full in Appendix A.
} 
of sufficient statistics, essentially deriving from the joint distribution of the income measure used as the tax base and marginal social utilities of income, and the distribution of the derivatives or elasticities of labour supplies with respect to tax rates and the lump sum. ${ }^{31}$

In the optimal tax analysis, the key relationships are the social welfare function and the households' indirect utility and earned income functions and their derivatives with respect to the tax parameters. We denote household indirect utility functions by $v(\cdot)$ and individual earnings functions by $y_{i}(\cdot), i=1,2$. In Appendix A, we present the details of the derivation of these functions and their properties, based on the household model presented in the previous section. Here, we simply assume:

The functions $v\left(\zeta ; w_{1}, w_{2}\right), y_{i}\left(\zeta ; w_{i}\right)$, where $\zeta$, to be specified, denotes a vector of tax variables, are increasing in $w_{i}, i=1,2$, and continuously differentiable in all their arguments.

\subsection{Tax systems}

The tax system pays households a uniform lump sum ${ }^{32}$ funded by revenue from taxes on the labour incomes of the two earners, aggregated across households, and offers a schedule of marginal tax rates. For any given tax system, households choose their optimal labour supplies and the resulting earnings form the basis for their allocation to a tax bracket with a given marginal tax rate. ${ }^{33}$

As well as the issue of the choice of tax base as between joint and individual incomes, also central is the structure of the rate scale, in particular whether the marginal tax rates applying to successive income brackets should be strictly increasing, or whether over at least some income ranges they should be decreasing. We refer to these as the "convex" and "non-convex" cases, respectively, to describe the types of budget sets in the gross income-net income/consumption plane to which they give rise. For the purposes of this paper, we focus on the convex case of a two-bracket piecewise linear system. ${ }^{34}$

By individual taxation we mean the case in which the two earners' incomes are taxed separately but according to the same tax schedule. This is in contrast to the case in which separate optimal tax schedules are found for primary and second earners, respectively,

\footnotetext{
31 However, the economic interpretation and empirical estimation of these sufficient statistics will closely depend on the underlying structural model.

32 This could be thought of as a standard child benefit.

33 A referee has pointed out that in this analysis we are restricting the form of the tax system to be either joint or individual, rather than finding the optimal system which may not correspond to either of these. We have discussed in the Introduction why we do not follow the mechanism design approach and focus on these two given systems because they seem to be empirically the most relevant, even if in practice the number and structure of the brackets differ from those assumed here, for example because of income-related transfers such as the earned income tax credit. We certainly agree that an important issue is how such systems should optimally be integrated into a formal piecewise linear tax system, but see that as the next step that is a priority for future work.

34 Apps et al. (2014) show that for wage distributions such as those currently prevailing in many OECD countries convex systems are highly likely to be welfare optimal.
} 
so-called selective or gender-based taxation. ${ }^{35}$ The main reason for constraining the rate schedules to be identical under individual taxation is that in practice, piecewise linear tax systems that are not joint are in fact overwhelmingly of the individual rather than selective kind. ${ }^{36}$ Moreover, if individual taxation yields higher social welfare than joint taxation under realistic assumptions, this result applies a fortiori to selective taxation, since removing the constraint that tax schedules must be identical cannot reduce the maximised value of social welfare and would be expected to increase it.

\subsection{Joint taxation}

There is a two-bracket piecewise linear $\operatorname{tax}^{37}$ on total household labour earnings, defined by $\zeta_{1}=\left(\alpha, \tau_{1}, \tau_{2}, \eta\right)$, where $\alpha$ is the uniform lump sum paid to every household, $\tau_{1}, \tau_{2}$ are the marginal tax rates in the lower and upper brackets of the tax schedules, and $\eta$ is the value of joint earnings defining the bracket limit. The household tax function is $T\left(y_{1 h}, y_{2 h}\right) \equiv T\left(y_{h}\right)$, with $y_{h}=\sum_{i=1}^{2} y_{i h}$, where households are indexed by $h \in \mathcal{H}$ and $y_{i h}$ is the labour income of individual $i=1,2$ in household $h$, with by definition $y_{2 h} \leq y_{1 h}$. This function is given by:

$$
\begin{aligned}
& T\left(y_{h}\right)=-\alpha+\tau_{1} y_{h} \quad y_{h} \leq \eta \\
& T\left(y_{h}\right)=-\alpha+\tau_{2} y_{h}+\left(\tau_{1}-\tau_{2}\right) \eta \quad y_{h}>\eta
\end{aligned}
$$

Given that all households face this identical budget constraint, it is straightforward to show that the optimal income $y_{h}^{*}$ for any one household must be in one of three possible subsets, ${ }^{38}$ which give a partition $\left\{\mathcal{H}_{0}, \mathcal{H}_{1}, \mathcal{H}_{2}\right\}$ of the index set $\mathcal{H}$ defined as follows:

$$
\begin{aligned}
& \mathcal{H}_{0}=\left\{h \mid 0 \leq y_{h}^{*}<\eta\right\} \\
& \left.\mathcal{H}_{1}=\left\{h \mid y_{h}^{*}=\eta\right)\right\} \\
& \mathcal{H}_{2}=\left\{h \mid y_{h}^{*}>\eta\right\}
\end{aligned}
$$

A household's optimum income may be either in the lower tax bracket, at the kink in the budget constraint defined by the bracket limit $\eta$, or in the upper tax bracket. In all of what follows we assume that we are dealing with tax systems in which each of these subsets is non-empty. Total household gross and net income are increasing

\footnotetext{
35 This was, for example, the approach taken by Boskin and Sheshinski (1983) and has been further developed by Alesina et al. (2011).

36 At the same time, it is possible to find examples of tax systems that contain selective elements. For example, in Australia, a portion of family benefits is withdrawn on the basis of the second earner's income. In Germany and the USA, contributions to social security, which are effectively part of the tax system, vary with the income of the second earner. See Apps and Rees (2009, Ch. 6).

37 For an extension of optimum piecewise linear taxation to the case of an arbitrary number $m \geq 2$ of tax brackets with only single-earner households, see Andrienko et al. (2016).

38 See Appendix A for details.
} 
continuously as we move from $\mathcal{H}_{0}$ to $\mathcal{H}_{1}$ and from $\mathcal{H}_{1}$ to $\mathcal{H}_{2}$, while they are both constant in $\mathcal{H}_{1}$. Important points to note are that:

- $\tau_{1}$ is a marginal tax rate for $h \in \mathcal{H}_{0}$ but defines an intra-marginal, non-distortionary tax for $h \in \mathcal{H}_{1} \cup \mathcal{H}_{2}$

- A marginal increase in $\eta$ has no effect for $h \in \mathcal{H}_{0}$, yields a net welfare gain for almost all $h \in \mathcal{H}_{1}$, and yields a lump sum income gain proportional to $\left(\tau_{2}-\tau_{1}\right)$ for $h \in \mathcal{H}_{2}$ (recall we assume that $\tau_{2}>\tau_{1}$ )

- In effect, for purposes of the tax analysis the household can be treated as a single individual, given that at each level of household income individual earnings are chosen so as to equate marginal effort costs, i.e. to minimise the cost of supplying that level of aggregate income. ${ }^{39}$

\subsubsection{Optimal tax analysis}

We define $\mathrm{d} F$ as the marginal density of household type $h$. The planner solves

$$
\max _{\alpha, \tau_{1}, \tau_{2}, \eta} W=\int_{h \in \mathcal{H}} S\left(v_{h}\right) \mathrm{d} F
$$

subject to the public sector budget constraint ${ }^{40}$

$$
\tau_{1}\left[\int_{h \in \mathcal{H}_{0}} y_{h} \mathrm{~d} F+\eta \int_{h \in \mathcal{H}_{1}} \mathrm{~d} F\right]+\int_{h \in \mathcal{H}_{2}}\left[\tau_{2} y_{h}+\left(\tau_{1}-\tau_{2}\right) \eta\right] \mathrm{d} F \geq \alpha
$$

where $S(\cdot)$ is a strictly concave and increasing function expressing the planner's distributional preferences over household utilities. From the first-order conditions characterising the optimal tax variables ${ }^{41}$ we can derive:

Proposition 1 The optimal tax system $\left(\alpha, \tau_{1}, \tau_{2}, \eta\right)$ can be characterised by the following conditions:

Marginal social utility of incomes:

$$
\int_{\mathcal{H}}\left(\sigma_{h}-1\right) \mathrm{d} F=0
$$

Lower bracket marginal tax rate:

$$
\tau_{1}^{*}=\frac{\int_{\mathcal{H}_{0}}\left(\sigma_{h}-1\right) y_{h}^{*} \mathrm{~d} F+\eta^{*} \int_{\mathcal{H}_{1} \cup H_{2}}\left(\sigma_{h}-1\right) \mathrm{d} F}{\int_{\mathcal{H}_{0}}\left(\partial y_{h} / \partial \tau_{1}\right) \mathrm{d} F}
$$

\footnotetext{
39 Again the details are in Appendix A.

40 We assume the aim of taxation is purely redistributive. Adding a nonzero revenue requirement would make no essential qualitative difference to the results.

41 Of course, exactly which households will be in which subsets is determined at the optimum, and depends on the values of the tax parameters. The following discussion characterises the optimal solution given the allocation of households to subsets that obtains at this optimum. As our later numerical analysis has shown us, it is not a trivial computational task to solve this model.
} 
Upper bracket marginal tax rate:

$$
\tau_{2}^{*}=\frac{\int_{\mathcal{H}_{2}}\left(\sigma_{h}-1\right)\left(y_{h}^{*}-\eta^{*}\right) \mathrm{d} F}{\int_{\mathcal{H}_{2}}\left(\partial y_{h} / \partial \tau_{2}\right) \mathrm{d} F}
$$

Determination of bracket limit:

$$
\int_{\mathcal{H}_{1}}\left\{\sigma_{h}\left[\left(1-\tau_{1}\right)-\frac{\partial \psi}{\partial y_{h}}\right]+\tau_{1}^{*}\right\} \mathrm{d} F=-\left(\tau_{2}^{*}-\tau_{1}^{*}\right) \int_{\mathcal{H}_{2}}\left(\sigma_{h}-1\right) \mathrm{d} F
$$

where $y_{h}^{*}$ denotes household income at the optimum and $\sigma_{h}$ is the marginal social utility of income to household $h$.

Condition (15) follows from the quasilinearity of the utility functions and is familiar from linear tax theory ${ }^{42}$ : Denoting the shadow price of the government budget constraint by $\lambda, \sigma_{h} \equiv S^{\prime}\left(v_{h}\right) / \lambda$ is the marginal social utility of income to household $h$ in terms of the numeraire, consumption, and so the optimal lump sum $\alpha$ equalises the average of the marginal social utilities of household income across the population to the marginal cost of the lump sum, which is 1 .

The strict concavity of $S(\cdot)$ implies that $\sigma_{h}$ is strictly decreasing in $v_{h}$. In the standard income tax model, with $v_{h}$ and $y_{h}$ co-monotonic, the lower tax bracket would contain not only the lower incomes but also the lower utilities. ${ }^{43}$ But because, as shown in the previous section, the household model of this paper does not imply this comonotonicity, the lower tax bracket may contain households with higher utility than households that are assigned, on the basis of joint income, to the higher bracket. This is of course simply a way of expressing the income-splitting advantage given to households with high primary and low second incomes under a joint taxation system.

In the two conditions corresponding to the tax rates $\tau_{1}^{*}, \tau_{2}^{*}$, the denominators are the frequency-weighted sums of the compensated derivatives of earnings with respect to the tax rates over the relevant subsets, and so give a measure of the marginal deadweight loss of the tax rate at the optimum, the efficiency cost of the tax, for households in the indicated subsets. The numerators give the equity effects.

The two terms in the numerator of (16) correspond to the two ways in which the lower bracket tax rate affects the contributions households make to funding the lump sum payment $\alpha$. Given their optimal household earnings $y_{h}^{*}$, the first term aggregates the effect of a marginal tax rate change on utility net of its marginal contribution to tax revenue over subset $\mathcal{H}_{0}$. The second term reflects the fact that the lower bracket tax rate is effectively a lump sum tax on income earned by the two higher income brackets, $\mathcal{H}_{1}$ and $\mathcal{H}_{2}$, since a change in this tax rate has only an intra-marginal effect, changing

\footnotetext{
42 See Sheshinski (1972).

43 This is also the case in the household model underlying the tax analysis of Boskin and Sheshinski (1983). Although this paper takes the important step of basing the tax analysis on a model of the two-person household, it retains the standard assumption that there are just two time uses, work, with productivity varying with the market wage, and leisure, with the same productivity across all households. This formulation preserves the co-monotonicity of income and utility across households that exists in the neo-classical model of the household as a single person. As we argued in the previous section, this co-monotonicity breaks down in a richer model that takes account of variations in productivity and prices in household production, with important implications for the results of the tax analysis, as we show in this and the following sections.
} 
the tax they pay at a rate given by $\eta$, while leaving their (compensated) labour supply unchanged.

Only the first of these two effects is present in the condition (17) corresponding to the higher tax rate. The portion of the income of the households in the higher tax bracket that is taxed at the rate $\tau_{2}^{*}$ is $\left(y_{h}^{*}-\eta^{*}\right)$, and so this weights the effect on social welfare net of the effect on tax revenue. Note that, unlike the case of linear income taxation, these numerator terms are not covariances, since the mean of $\sigma_{h}$ over each of the subsets is not 1 . They are commonly referred to as "distributional characteristics".

Comparing the numerator terms in (16) and (17) shows that each contains the term $\eta^{*} \int_{\mathcal{H}_{2}}\left(\sigma_{h}-1\right) \mathrm{d} F$, but with opposite signs. This suggests that the greater the contribution of the lump sum tax on upper income bracket households arising from the tax rate $\tau_{1}^{*}$, the smaller is the tax rate $\tau_{2}^{*}$, and so the smaller is the distortionary effect on labour supplies in this bracket, other things being equal. ${ }^{44}$ Note also that, other things equal, the more sharply $y_{h}^{*}$ increases across households in the upper bracket the greater will be the tax rate $\tau_{2}^{*}$, implying that tax rates are sensitive to growing inequality in the form of sharp increases in top incomes. ${ }^{45}$

Condition (18) corresponding to the optimal bracket limit $\eta^{*}$, has the following interpretation. The left hand side represents the marginal social benefit of a relaxation of the bracket limit. This consists first of all of the gain to all those households that are effectively constrained at $\eta^{*}$, in the sense that they are prepared to increase earnings if these are taxed at $\tau_{1}^{*}$ but not at $\tau_{2}^{*}$ - the return to additional labour supply at $\tau_{1}^{*}$, but not $\tau_{2}^{*}$, exceeds its marginal utility cost. ${ }^{46}$ The first term in brackets on the left hand side is the net marginal benefit to these consumers, weighted by their marginal social utilities of income. The second term is the rate at which tax revenue increases given the increase in gross income resulting from the relaxation of the bracket limit.

The right hand side gives the marginal social cost of the relaxation. Since $\left(\tau_{2}^{*}-\tau_{1}^{*}\right)>$ 0 by assumption, all households $h \in \mathcal{H}_{2}$ receive a lump sum income increase at this rate and this is weighted by the deviation of the marginal social utility of income of these households from the average. As long as the sum of these deviations, weighted by the frequencies of the household types, is negative, the marginal cost of the bracket limit increase is a worsening in the equity of the income distribution. The condition then trades off the social value of the gain to households in $\mathcal{H}_{1}$ against the social cost of making households in $\mathcal{H}_{2}$ better off.

\subsection{Individual taxation}

There is a two-bracket piecewise linear tax system now applied to individual labour earnings, defined by $\zeta_{2}=\left(a, t_{1}, t_{2}, y\right)$, where $a$ is again a uniform lump sum paid to every household, $t_{1}, t_{2}$ are the marginal tax rates in the lower and upper brackets, and

\footnotetext{
44 It is this trade-off which can lead to the non-convex case in which the upper bracket tax rate is optimally lower than that in the lower bracket, as found in the simulations by Slemrod et al. (1994). For further discussion, see Apps et al. (2014).

45 See Andrienko et al. (2016) for more on this.

46 For the details again see Appendix A.
} 
$y$ is the value of individual earnings defining the bracket. Thus, the individual tax function $\hat{T}\left(y_{i h}\right)$ is defined by:

$$
\begin{aligned}
& \hat{T}\left(y_{i h}\right)=t_{1} y_{i h} \quad y_{i h} \leq y \\
& \hat{T}\left(y_{i h}\right)=t_{2} y_{i h}+\left(t_{1}-t_{2}\right) y \quad y_{i h}>y \quad h \in \mathcal{H}
\end{aligned}
$$

and the household tax function is $T\left(y_{1 h}, y_{2 h}\right) \equiv-a+\sum_{i=1}^{2} \hat{T}\left(y_{i h}\right)$. Given that, by definition, $y_{2 h}^{*} \leq y_{1 h}^{*}$ for every household, and that under individual taxation everyone faces the same tax schedule, it is easy to see that there are now six possible subsets of households which form a partition $\left\{H_{0}, H_{1}, \ldots, H_{5}\right\}$ of the index set $\mathcal{H}$, defined by

$$
\begin{aligned}
& H_{0}=\left\{h \mid 0 \leq y_{i h}^{*}<y, i=1,2\right\} \\
& H_{1}=\left\{h \mid y_{2 h}^{*}<y=y_{1 h}^{*}\right\} \\
& H_{2}=\left\{h \mid y_{i h}^{*}=y, i=1,2\right\} \\
& H_{3}=\left\{h \mid y_{2 h}^{*}<y<y_{1 h}^{*}\right\} \\
& H_{4}=\left\{h \mid y_{2 h}^{*}=y<y_{1 h}^{*}\right\} \\
& H_{5}=\left\{h \mid y_{i h}^{*}>y, i=1,2\right\}
\end{aligned}
$$

In $H_{0}-H_{2}$ both individuals pay the lower tax rate, in $H_{3}$ and $H_{4}$ the primary earner alone pays the higher tax rate, and in $H_{5}$ both pay the higher tax rate.

There are two important differences to the joint taxation case, resulting from the obviously finer partition of households based on individual reactions to the tax system. First, one or both individuals in households with a total income large enough to place them in the upper tax bracket under joint taxation may be in the lower bracket under individual taxation; and secondly, high-wage primary earners in households with a low enough second income may be placed in the lower bracket of the joint tax system, while in the individual system the primary earner will be in the upper bracket and the second earner in the lower. ${ }^{47}$

That is, the individual tax system corrects two types of errors that the joint tax system makes. Taking joint income as the tax base assigns to lower-wage two-earner households a rank in the joint income distribution that is too high relative to their position in the utility ranking; and at the same time the income-splitting advantage to a high-wage primary earner allows the household to place itself in a position in the income ranking that is too low relative to its position in the utility ranking. This second type of error is particularly significant when there is a high degree of inequality in primary earner wages. This is clearly brought out in the numerical example of the following section.

Of course, neither of these errors could arise if household well-being increased monotonically with joint income, but the purpose of the model in the previous section was to show that this cannot in general be assumed. The numerical analysis in the

\footnotetext{
47 This is a further respect in which this paper extends the results of Boskin and Sheshinski (1983), due this time to replacing their linear taxation model with a piecewise linear tax system. While confirming their result of the welfare superiority of individual (or, in their case, selective) taxation, it gives greater insight into the structure of the tax system that increases its relevance for actual tax policy.
} 
following section, which calculates optimal taxes on the basis of two versions of that model, shows how the equity effects arising from the correction of these errors can reinforce the efficiency effects and ensure a welfare dominance of individual taxation that is robust to a wide range of assumptions consistent with the empirical evidence.

\subsubsection{Optimal tax analysis}

To shorten notation denote the subset $H_{i} \cup H_{j}$ by $H_{i j}$, and $H_{i} \cup H_{j} \cup H_{k}$ by $H_{i j k}, i, j, k=0, \ldots, 5, i \neq j, i, j \neq k$. The planner solves

$$
\max _{a, t_{1}, t_{2}, y} W=\int_{\mathcal{H}} S\left(v_{h}\right) \mathrm{d} F
$$

subject now to the public sector budget constraint

$$
\int_{H_{012}} t_{1} y_{h} \mathrm{~d} F+\int_{H_{34}}\left[t_{2} y_{1 h}+t_{1} y_{2 h}+\left(t_{1}-t_{2}\right) y\right] \mathrm{d} F+\int_{H_{5}}\left[t_{2} y_{h}+2\left(t_{1}-t_{2}\right) y\right] \mathrm{d} F \geq a
$$

where again $y_{h}=\sum_{i=1}^{2} y_{i h}$.

In what follows, it will be useful to denote by $\mu_{i h}$ the value of a relaxation of the bracket limit to an individual at the kink in the budget constraint. ${ }^{48}$ Also, to shorten notation we denote $\sigma_{h}-1$ by $\delta_{h}$. Then $\delta_{h}>(<) 0$ according as household $h$ is relatively worse (better) off in utility terms than the subset of households for which $\sigma_{h}=1$.

From the first-order conditions for an optimal solution ${ }^{49}$ we derive:

Proposition 2 The optimal tax system $\left(a, t_{1}, t_{2}, y\right)$ is characterised by the conditions: Marginal social utility of incomes:

$$
\int_{\mathcal{H}} \delta_{h} \mathrm{~d} F=0
$$

Lower bracket marginal tax rate:

$$
t_{1}^{*}=\frac{\int_{H_{0}} \delta_{h} y_{h}^{*} \mathrm{~d} F+\int_{H_{13}} \delta_{h}\left(y_{2 h}^{*}+y^{*}\right) \mathrm{d} F+2 y^{*} \int_{H_{245}} \delta_{h} \mathrm{~d} F}{\int_{H_{0}} \partial y_{1 h} / \partial t_{1} \mathrm{~d} F+\int_{H_{013}} \partial y_{2 h} / \partial t_{1} \mathrm{~d} F}
$$

Upper bracket marginal tax rate:

$$
t_{2}^{*}=\frac{\int_{H_{345}} \delta_{h}\left(y_{1 h}^{*}-y^{*}\right) \mathrm{d} F+\int_{H_{5}} \delta_{h}\left(y_{2 h}^{*}-y^{*}\right) \mathrm{d} F}{\int_{H_{345}} \partial y_{1 h} / \partial t_{2} \mathrm{~d} F+\int_{H_{5}} \partial y_{2 h} / \partial t_{2} \mathrm{~d} F}
$$

\footnotetext{
48 The counterpart of the term $\left(1-\tau_{1}\right)-\partial \psi / \partial y_{h}$ in the joint taxation case, but here the term represents the value of a relaxation of the constraint to each individual in the household. See Appendix for further discussion.

49 Again, exactly which households will be in which subsets is determined at the optimum and depends on the values of the tax parameters.
} 
Determination of bracket limit:

$$
\begin{gathered}
\int_{H_{12}}\left(\sigma_{h} \mu_{1 h}+t_{1}\right) \mathrm{d} F+\int_{H_{24}}\left(\sigma_{h} \mu_{2 h}+t_{1}\right) \mathrm{d} F= \\
-\left(t_{2}-t_{1}\right)\left[\int_{H_{34}} \delta_{h} \mathrm{~d} F+2 \int_{H_{5}} \delta_{h} \mathrm{~d} F\right]
\end{gathered}
$$

The first condition, since it involves the entire population, is exactly as for joint taxation. The remaining three conditions have basically the same interpretation as before, but of course the relevant integrals are now over subsets of individuals reflecting the partition defined in (21)-(26).

\subsection{Implications of the optimality conditions for the comparison of the two systems}

We can use this tax analysis to give an idea of how the switch from joint to individual taxation could affect the tax structure. First note that the denominator in the expression for $t_{1}^{*}$ will tend to contain more lower-income second earners than that for $\tau_{1}^{*}$, since the subset $H_{013}$ contains second earners who, because they are in households with high-wage primary earners, would under joint taxation be in the upper tax bracket. The subset $H_{345}$ in the denominator for $t_{2}^{*}$ will tend to include more high-wage primary earners, who have lost the income-splitting advantage they obtain under joint taxation. Other things equal therefore, this would lead us to expect a greater difference between the two tax rates, or higher marginal rate progressivity, in the case of individual taxation, given the stylised fact that labour supply elasticities are lower for primary than for second earners. ${ }^{50}$

A similar point can be made with respect to the numerators of the expressions for the upper bracket tax rates in the two cases, which represent the equity terms. In the expression (17) for $\tau_{2}^{*}$, we have the term $\int_{\mathcal{H}_{2}} \delta_{h}\left(y_{h}^{*}-\eta^{*}\right) \mathrm{d} F$, while for $t_{2}^{*}$ we have $\int_{H_{345}} \delta_{h}\left(y_{1 h}^{*}-y^{*}\right) \mathrm{d} F+\int_{H_{5}} \delta_{h}\left(y_{2 h}^{*}-y^{*}\right) \mathrm{d} F$. The subset $\mathcal{H}_{2}$ will contain lower-wage two-earner households with close to average welfare weights and therefore $\delta_{h}$-values close to zero, while the differences $\left(y_{h}^{*}-\eta^{*}\right)$ for households with strongly negative $\delta_{h}$-values will be diminished by the fact that the values of joint income $y_{h}^{*}$ will be relatively lower for households with little or no income from the second earner. In contrast, the subset $H_{345}$ contains only the highest income primary earners, and $H_{5}$ only the highest income primary and second earners, with (as shown by the empirical wage distributions in Fig. 1) very large differences $\left(y_{i h}^{*}-y^{*}\right)$ between their incomes and the bracket limit. This gives an additional reason to expect that the individual tax system will be very much more marginal rate progressive than the joint system.

\footnotetext{
50 We should note that the empirical estimates of elasticities are gender-based-female labour supply elasticities are higher than male-whereas the distinction here between primary and second earners is on the basis of earned income rather than gender. We would argue, however, that the high female elasticities are based on role rather than gender. Also, as pointed out earlier, it is still the case that the large majority of second earners are women. For insightful empirical work on this, see McClelland et al. (2014).
} 
Finally, we can compare the results for the optimal bracket limits under the alternative tax systems. The underlying principle is of course the same in each case: the optimal bracket limit trades off the marginal gain to those individuals who are effectively constrained at the kink in their budget constraints against the loss in equity from the intra-marginal lump sum gain in income to those in the higher tax bracket. The key point is that, from the point of view of a ranking according to marginal social utility of income, individual taxation leads to a more equitable sorting of individuals into tax brackets, and the overall result is a reduction in the optimal bracket limit as we move from joint to individual taxation.

Thus, suppose we move from a joint taxation system with a bracket limit of $\eta^{*}$ to an individual tax system with a bracket limit on individual income of $\eta^{*} / 2$. An important change takes place in the composition of the top tax bracket. Primary earners with incomes $y_{1}>\eta^{*} / 2$ and with partners whose incomes are less than $\eta^{*}-y_{1}$, who were formally in the lower bracket, will now move into the top tax bracket. This will reduce the average of the marginal social utilities of income in the top bracket, implying that a reduction in the bracket limit will yield a net equity gain from the lump sum increase in tax revenue that results.

Moreover, as can easily be seen in condition (31), since the difference between the tax rates in the lower and upper brackets increases, as just discussed, this increases the absolute value of the gain from a marginal increase in the bracket limit to those in the upper bracket, increasing the marginal social cost of such an increase, and this will also lead to a reduction in the bracket limit.

These remarks are confirmed by the numerical analysis of the next section, where the differences between the two tax systems, in marginal rate progressivity as well as in the bracket limits, are striking. We highlight these differences as a major reason for the welfare superiority of individual over joint taxation systems, given the very high degree of inequality exhibited by the empirical primary earner wage distribution illustrated in Fig. 1. Joint taxation allows high-wage primary earners to reduce their tax burden by having the second earner in the household reduce her labour supply or leave the labour force altogether. Individual taxation removes this opportunity and so allows the tax system the possibility of significantly more redistribution across the highly unequal primary wage distribution, as well as yielding the well-known efficiency gain.

\section{Numerical analysis}

A calibrated version of a theoretical model cannot of course be a blueprint for tax reform in any actual economy. However, since Mirrlees (1971), Stern (1976) and Tuomala (1984), there has been a tradition in optimal tax theory of using plausibly calibrated models to clarify the qualitative implications of particular tax models and provide insights which, hopefully, can be followed up in richer empirical models. ${ }^{51}$

\footnotetext{
51 For example, in an empirical study using a stochastic dynamic OLG model calibrated to the German economy, Fehr and Ujhelyiova (2012) show that a move from joint to individual taxation accompanied by subsidisation of bought-in child care increases welfare for all productivity levels of workers.
} 
Following this tradition, we draw on household survey data for a sample of two-parent families to calibrate models nested within the following general empirical specification of the theoretical model set out in Sect. 2. We then use the models to solve for the optimal tax parameters of joint and individual taxation and to compute aggregate measures of social welfare under each system.

\subsection{Empirical specification}

We solve for the optimal tax parameters by maximising a social welfare function of the form $\left[\sum_{h=1}^{H} u_{h}^{1-\pi}\right]^{1 /(1-\pi)}$, with $\pi$ a measure of inequality aversion.

The quasilinear utility function introduced in Sect. 2 is specified as

$$
u_{h}=x_{h}-\left(y_{1 h} / w_{1 h}\right)^{\alpha_{1}}+z_{h}^{\alpha_{2}} \quad h \in \mathcal{H}
$$

with $\alpha_{1}=\left(1+e_{1}\right) / e_{1}>1$, where $e_{1}$ is the elasticity of labour supply with respect to the net wage of the primary earner, and $\alpha_{2} \in(0,1)$. All households are assumed to have the same preferences and therefore the same parameters in the household utility function.

Child care, $z$, is the output of a CES production function:

$$
z_{h}=\gamma\left[\beta_{h}\left(k_{h} c_{h}\right)^{\rho_{h}}+\left(1-\beta_{h}\right)\left(q_{h} b_{h}\right)^{\rho_{h}}\right]^{1 / \rho_{h}} \quad h \in \mathcal{H}
$$

where $\gamma>0$ is a scaling factor, the parameter $\rho_{h}$ determines the elasticity of substitution between the second earner's home care input and bought-in child care, $1 /\left(1-\rho_{h}\right)$, and $\beta_{h} \in(0,1)$.

Following the convention of the labour supply literature, we set market productivities to respective wage rates and we define market consumption, $x$, as a Hicksian composite good and choose it as numeraire with price set to 1 .

We solve for the optimal tax parameters under joint and individual taxation for two models, labelled Models 1 and 2, that are nested within the general empirical specification in (32) and (33). The models incorporate different assumptions on the productivity variable, $k_{h}$, for which information is missing in available household survey data sets, as well as on the exogenous factors driving heterogeneity. The assumptions of each model and the parameter values selected to generate labour supplies that broadly match the data are set out below.

\subsection{Data}

The sample of two-parent families is drawn from the Australian Bureau of Statistics (ABS) 2009-2010 Survey of Income and Housing. ${ }^{52}$ We first construct a percentile primary wage distribution from the data for primary earnings and hours of work. The

\footnotetext{
52 See Australian Bureau of Statistics (2012). The sample is selected on the criteria that a child aged from 0 to 9 years is present and the primary earner is aged from 25 to 59 years and works at least $25 \mathrm{~h} /$ week for a wage of at least $\$ 15.00$ (the minimum wage in 2010). The sample contains 1860 records.
} 


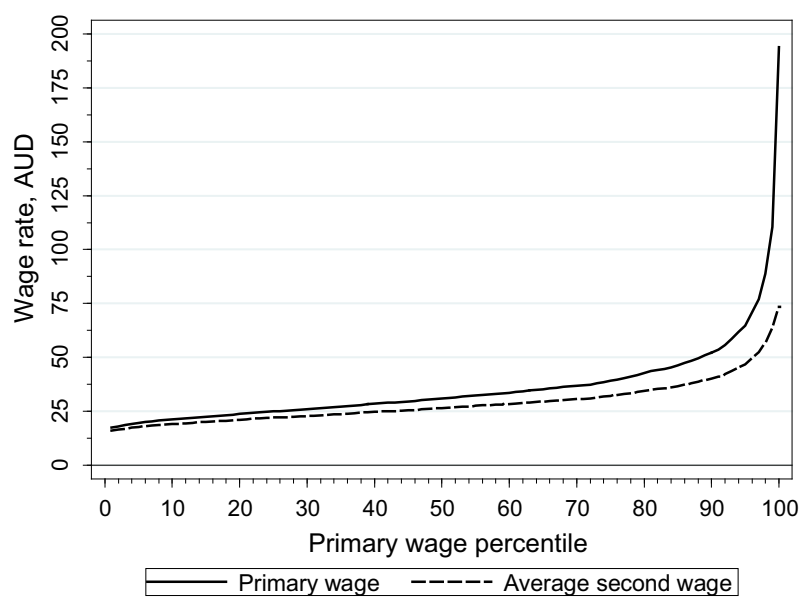

Fig. 1 Percentile wage distributions

wage in each percentile is calculated as average gross hourly earnings, with hours smoothed across the distribution. ${ }^{53}$ A second profile representing the average second earner wage at each primary wage percentile is constructed from the data on second earnings and hours. ${ }^{54}$ Both profiles are plotted in Fig. 1.

The smoothed profile of primary earner hours is relatively flat, rising only slightly across the primary wage distribution, with an overall average of around $8 \mathrm{~h} /$ day for a 5 day working week. We find that $e_{1}=0.1$ generates a primary hours profile across the primary wage distribution that broadly matches the data and we therefore base the simulations on this primary wage elasticity, which is probably at the higher end of empirical estimates of prime age male labour supply elasticities.

The smoothed profile of second earner hours, while relatively flat, tends to rise across the middle percentiles and then decline towards the top percentiles, with an overall mean close to $4.5 \mathrm{~h} /$ day. However, in contrast to primary hours, there is a high degree of heterogeneity. Over a third of second earners work part time with widely varying hours, around a third work full time and the remainder are not in the workforce. Very little of the variation in second hours can be explained by wage rates or demographics at a given primary wage.

As a reference for the data on second earner labour supplies, we construct profiles of second hours based on splitting the sample according to median second hours across the primary wage distribution. Records with second hours below the median are labelled "H1" and those with hours at or above the median, "H2". Parameter values are selected for the simulations which can generate labour supplies that approximate the average hours of $\mathrm{H} 1$ and $\mathrm{H} 2$ households by falling broadly within the range of 1.0 and $2.0 \mathrm{~h}$ for the former and 7.0 and $8.0 \mathrm{~h}$ for the latter. The time constraint is set to $10 \mathrm{~h} /$ day.

\footnotetext{
53 We apply the lowess method to obtain a smoothed profile.

54 We correct for selectivity bias based on an analysis of predicted wage rates for participant and nonparticipant subsamples within quintiles of the primary wage distribution.
} 


\subsection{Model 1}

Model 1 is based on assumptions consistent with empirical studies showing that child outcomes improve with maternal human capital and that parental investment in quality child care and education increases with family resources, as discussed in Sect. 2. The productivity of time spent on child care, in terms of achieving child outcomes, is assumed to be given by the mother's wage and we therefore set $k_{h}=w_{2 h}$ for $\tilde{\kappa}=0$. The quality of market child care chosen by the household, $q_{h}$, is, in turn, assumed to match that of the second earner's own child care time. All households have the same production parameters $\gamma, \beta$ and $\rho$, in addition to the same preference parameters.

Heterogeneity in second earner labour supply can be introduced by random variation in either $k_{h}$ or $p_{h} .{ }^{55}$ We therefore have $k_{h}=w_{2 h}+\kappa_{h}$ and $p_{h}=w_{2 h}+\varepsilon_{h}$, with $\kappa_{h}$ and $\varepsilon_{h}$ the household's realisations of $\tilde{\kappa}$ and $\tilde{\varepsilon}$, respectively. We define $p_{z}$ as the implicit price of a unit of child care output, $z_{h}$, which is equal to its marginal production cost, determined by the net-of-tax wage rates, prices of bought-in care $p_{h}$ and marginal productivities, the derivatives of (33). This implicit price is of course independent of output $z_{h}$ given the constant returns assumption.

The first step is to construct a pre-tax benchmark population of households giving an optimal second earner labour supply at every wage pair of $5 \mathrm{~h} /$ day (which is marginally above the after-tax overall mean of $4.5 \mathrm{~h}$ ) for $\tilde{\kappa}=0, \tilde{\varepsilon}=0$. For this outcome, we set $\beta=0.5$. We also set $\gamma=2$ to give $p_{z}=1$ at the benchmark equilibrium. Given that introducing labour supply heterogeneity by varying $k_{h}$ will tend to bias the results towards individual taxation, by making the $\mathrm{H} 1$ household better off at any given wage pair, we report results for variation in $p_{h}$ only.

We perturb the benchmark labour supplies by varying $p_{h}$ above and below its benchmark value, $p_{h}=w_{2 h}$, by the same percentage at each wage pair, ${ }^{56}$ solving for the household equilibria in each case. In this way, we generate subsamples of households in which second earner labour supplies are, respectively, above and below the benchmark median, corresponding to the households facing lower/higher prices. This provides us with a population of heterogeneous households for which we then compute optimal piecewise linear tax systems based on joint and individual incomes, respectively. Figure 2 illustrates this procedure for variation in $p_{h}$.

Given the above specifications, it is easy to show that, at any wage pair, an equilibrium of the household that is fully symmetric with respect to bought-in and parental child care, and yields an equal division of available time between market and household work, must look like that shown in the figure. The marginal value product curves of $b_{h}$ and $c_{h}$ are identical and therefore mirror images of each other when $c_{h}$ is measured from left to right and $b_{h}$ measured in the reverse direction, and setting $p_{h}=w_{2 h}$ ensures that the curves intersect at $b_{h}=c_{h}=5$, where condition (7) of Sect. 2 is satisfied. Then, perturbing this equilibrium by raising $p_{h}$ reduces $b_{h}$, and therefore

\footnotetext{
55 In contrast to $k_{h}$ for which data are entirely missing, there is information on $p_{h}$ and $q_{h}$. However, the data for these variables indicate a very high degree of variation in the price of an hour of child care, $p_{h}$, of a given quality, as noted previously.

56 We restrict the variations in $p_{h}$ above and below $w_{2 h}$ to the same percentage to facilitate comparisons across the results.
} 


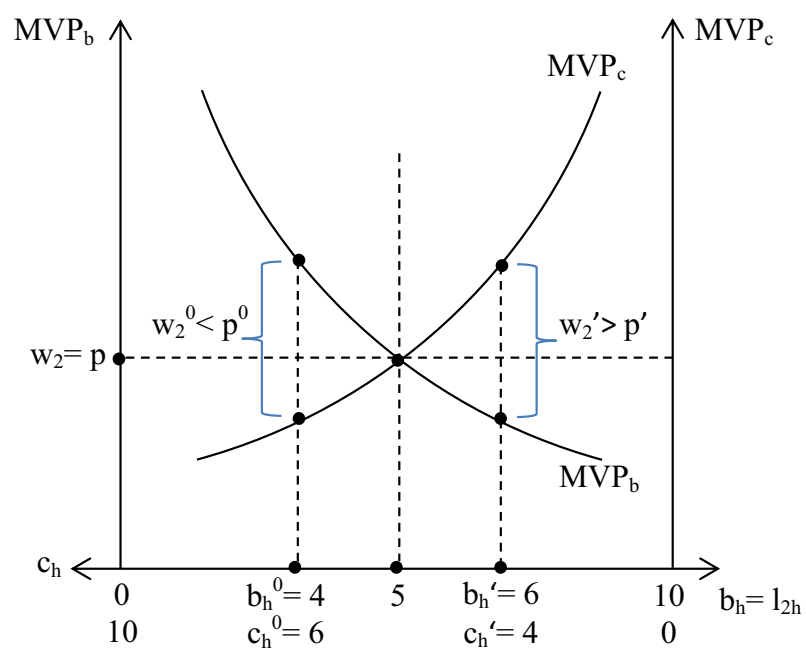

Fig. 2 Model 1

market labour supply $l_{2 h}$, and increases $c_{h}$, while reducing $p_{h}$ has the converse effect. The equilibrium division of time use between market labour supply/bought-in care and parental child care corresponds to the point at which the vertical distance between the curves is equal to the difference between $w_{2 h}$ and $p_{h}$. Thus, this simple, symmetric benchmark model provides us with a very convenient way of generating whole populations of heterogeneous households for varying distributions of the price of bought-in child care.

We solve for the optimal tax systems first for two degrees and then for four degrees of price variation, respectively. With two degrees of price variation, we have the binary price distribution $p \in\left\{p^{1}, p^{2}\right\}$ with $100 \mathrm{H} 1$ households facing the higher price $p^{2}$ and $100 \mathrm{H} 2$ households facing the lower price $p^{1}$. Each degree of variation is again expressed as a proportion of the second earner wage at each percentile.

Table 1 reports results for a price variation of $\pm 15 \%$. The table compares the optimal marginal tax rates and lump sum, the bracket point and aggregate social welfare, SW, under piecewise linear joint and individual taxation for $\rho=0.82$, a value which generates second earner labour supplies that approximate the data means of the $\mathrm{H} 1$ and $\mathrm{H} 2$ subsamples. The results for the optimal tax parameters show that individual taxation is consistently superior to joint taxation for $\pi=0.2$ to 0.6 and becomes increasingly superior as the degree of inequality aversion, $\pi$, rises.

The lower child care price for $\mathrm{H} 2$ can be interpreted as equivalent to a child care subsidy. The effect on the benchmark equilibrium price, $p_{z}=1$, is minimal for both $\mathrm{H} 1$ and $\mathrm{H} 2$ because the productivity/quality of home and bought-in care are equal. For example, for $\pi=0.3$, the median price for $\mathrm{H} 1$ rises to 1.09 under both joint and individual taxation, and for $\mathrm{H} 2$, it falls to 0.92 under joint taxation and to 0.91 under individual taxation. Consequently, there is very little household utility reranking across the distribution of primary income, despite the wide gap in market hours generated by the variation in $p_{h}$. 
Table 1 Model 1: Child care price variation: \pm 0.15 , with $\rho=0.82$

\begin{tabular}{lllllllll}
\hline$\pi$ & Tax system & $\tau_{1}, t_{1}$ & $\tau_{2}, t_{2}$ & $\alpha, a$ & $\mathrm{Bkt}^{\mathrm{a}}$ & $\mathrm{SW}$ & $\mathrm{H} 1 \mathrm{~h}^{\mathrm{b}}$ & $\mathrm{H} 2 \mathrm{~h}^{\mathrm{c}}$ \\
\hline 0.2 & Joint & 0.03 & 0.10 & 3491 & 97 & 86,428 & 1.75 & 7.42 \\
& Individual & 0.02 & 0.43 & 4926 & 96 & 86,661 & 1.87 & 7.59 \\
0.3 & Joint & 0.04 & 0.12 & 4550 & 97 & 220,744 & 1.64 & 7.26 \\
& Individual & 0.02 & 0.44 & 6760 & 88 & 221,836 & 1.87 & 7.59 \\
0.4 & Joint & 0.06 & 0.13 & 6522 & 97 & 773,223 & 1.43 & 6.91 \\
& Individual & 0.03 & 0.49 & 8446 & 87 & 779,079 & 1.75 & 7.42 \\
0.5 & Joint & 0.08 & 0.22 & 7521 & 99 & $4,488,209$ & 1.34 & 6.71 \\
& Individual & 0.03 & 0.53 & 9246 & 86 & $4,533,925$ & 1.75 & 7.42 \\
0.6 & Joint & 0.08 & 0.24 & 8471 & 99 & $63,029,740$ & 1.25 & 6.52 \\
& Individual & 0.04 & 0.56 & 10,517 & 86 & $63,830,748$ & 1.64 & 7,26 \\
\hline
\end{tabular}

${ }^{\mathrm{a}}$ Income percentile of bracket point; ${ }^{\mathrm{b}}$ median $\mathrm{H} 1$ second hours; ${ }^{\mathrm{c}}$ median $\mathrm{H} 2$ second hours

Table 2 Model 1: Child care price variation: \pm 0.25 , with $\rho=0.7$

\begin{tabular}{lllllllll}
\hline$\pi$ & Tax system & $\tau_{1}, t_{1}$ & $\tau_{2}, t 2$ & $\alpha, a$ & $\mathrm{Bkt}^{\mathrm{a}}$ & $\mathrm{SW}$ & $\mathrm{H} 1 \mathrm{~h}^{\mathrm{b}}$ & $\mathrm{H} 2 \mathrm{~h}^{\mathrm{c}}$ \\
\hline 0.2 & Joint & 0.05 & 0.14 & 5778 & 97 & 87,302 & 1.80 & 7.41 \\
& Individual & 0.04 & 0.43 & 6908 & 95 & 87,491 & 1.87 & 7.50 \\
0.3 & Joint & 0.07 & 0.19 & 7876 & 97 & 223,061 & 1.67 & 7.20 \\
& Individual & 0.05 & 0.48 & 8885 & 95 & 224,236 & 1.80 & 7.41 \\
0.4 & Joint & 0.09 & 0.21 & 9875 & 97 & 781,724 & 1.55 & 7.00 \\
& Individual & 0.06 & 0.52 & 10,263 & 92 & 786,120 & 1.73 & 7.31 \\
0.5 & Joint & 0.11 & 0.22 & 11,796 & 97 & $4,539,888$ & 1.44 & 6,79 \\
& Individual & 0.06 & 0.53 & 11,639 & 87 & $4,574,157$ & 1.73 & 7.31 \\
0.6 & Joint & 0.13 & 0.34 & 13,704 & 99 & $63,786,656$ & 1.35 & 6.55 \\
& Individual & 0.07 & 0.56 & 12,875 & 87 & $64,393,808$ & 1.67 & 7.22 \\
\hline
\end{tabular}

${ }^{\mathrm{a}}$ Income percentile of bracket point; ${ }^{\mathrm{b}}$ median $\mathrm{H} 1$ second hours; ${ }^{\mathrm{c}}$ median $\mathrm{H} 2$ second hours

Table 2 reports results for a higher degree of price variation of $\pm 25 \%$. To match the data on labour supplies when the degree of price variation rises/falls from \pm 15 to $\pm 25 \%$, it is necessary to reduce the value of $\rho$ to 0.7 . The explanation is straightforward. To obtain labour supplies within ranges consistent with the data as the degree of price variation rises, we need to assume that home and bought-in care are less close substitutes, as implied by a lower value for $\rho$.

The results again show that individual taxation is consistently superior to joint taxation, but with some interesting minor differences. The optimal tax structure tends to be less progressive because the higher $25 \%$ reduction in the price of bought-in care (equivalent to a larger child care subsidy for $\mathrm{H} 2$ ), has the effect of making $\mathrm{H} 2$ households relatively better off. Consequently, marginal tax rates across both brackets are slightly higher for most values of $\pi$. The gaps between the median values of $p_{z}$ 
Table 3 Model 1: Child care price variation: $\pm 0.25 ; \pm 0.50$, with $\rho=0.5$

\begin{tabular}{lllllllll}
\hline$\pi$ & Tax system & $\tau_{1}, t_{1}$ & $\tau_{2}, t_{2}$ & $\alpha, a$ & $\mathrm{Bkt}^{\mathrm{a}}$ & $\mathrm{SW}$ & $\mathrm{H} 1 \mathrm{~h}^{\mathrm{b}}$ & $\mathrm{H} 2 \mathrm{~h}^{\mathrm{c}}$ \\
\hline 0.2 & Joint & 0.07 & 0.22 & 8252 & 97 & 209,981 & 1.61 & 7.86 \\
& Individual & 0.06 & 0.44 & 8671 & 96 & 210,313 & 1.64 & 7.90 \\
0.3 & Joint & 0.10 & 0.24 & 11,218 & 97 & 607,343 & 1.51 & 7.73 \\
& Individual & 0.08 & 0.50 & 11,286 & 95 & 609,026 & 1.58 & 7.82 \\
0.4 & Joint & 0.14 & 0.34 & 15,281 & 97 & $2,511,256$ & 1.40 & 7.52 \\
& Individual & 0.10 & 0.56 & 13,558 & 95 & $2,521,040$ & 1.51 & 7.73 \\
0.5 & Joint & 0.16 & 0.36 & 17,216 & 97 & $18,383,842$ & 1.35 & 7.42 \\
& Individual & 0.11 & 0.56 & 15,204 & 93 & $18,475,026$ & 1.49 & 7.67 \\
0.6 & Joint & 0.18 & 0.37 & 19,097 & 97 & $365,424,644$ & 1.31 & 7.30 \\
& Individual & 0.13 & 0.59 & 17,301 & 92 & $367,662,752$ & 1.44 & 7.57 \\
\hline
\end{tabular}

${ }^{\mathrm{a}}$ Income percentile of bracket point; ${ }^{\mathrm{b}}$ median $\mathrm{H} 1$ second hours for $p=p \pm 0.50 w_{2} ;{ }^{\mathrm{c}}$ median $\mathrm{H} 2$ second hours for $p=p \pm 0.50 w_{2}$

for $\mathrm{H} 1$ and $\mathrm{H} 2$ under both joint and individual taxation, while slightly larger, remain relatively small, and so the degree of household utility re-ranking is minimal.

Table 3 extends the analysis by combining two degrees of price variation, which gives four rather than two relative prices for child care in each percentile, that is, $p_{h} \in\left\{p^{1}, \ldots, p^{4}\right\}$, which increases the total number of household records from 200 to 400 . The table reports the results for price variations of \pm 25 and $\pm 50 \%$ above and below the benchmark price. To match the data when the degree of price variation rises to $\pm 50 \%$, it is necessary to set $\rho=0.5$. Again we find individual taxation remains consistently superior to joint taxation and becomes increasingly so as $\pi$ rises from 0.2 to $0.6 .^{57}$

The most striking feature of the results, apart from the complete dominance of individual taxation, is the change in the structure of tax rates as we switch from joint to individual taxation. The top marginal tax rate under individual taxation is consistently much higher than that under joint taxation, and the threshold of the top bracket is significantly lower. These results illustrate numerically the points made in Sect. 3.4 above: The changes in the composition of the tax brackets resulting from the move from joint to individual taxation change the optimality conditions for the marginal tax rates and bracket limit in such a way as to greatly increase the overall progressivity of the tax system.

Importantly, given the shape of the wage distribution, a progressive individual income tax redistributes the tax burden from the lower and middle to the top wage percentiles. The differences in top marginal tax rates under the two systems highlight the extent of the income-splitting gain to top primary wage earners under joint taxation, and the extent to which this constrains the distribution of tax burdens. Furthermore, as discussed in Sect. 3, including second earners with relatively higher compensated elasticities in the higher tax bracket under joint taxation reduces the marginal rate

57 Additional results are available from the authors. 
progressivity of the tax system, since it raises the absolute value of the denominator in the expression determining the optimal tax rate. It is counter-productive in terms of both equity and efficiency to use a joint tax system to impose a higher marginal rate on second earners across the lower and middle percentiles of the wage distribution, while the marginal tax rate on high primary wage earners is set at relatively low levels.

\subsection{Model 2}

Model 2 incorporates the assumptions on domestic time productivity and the quality and price of bought-in child care time adopted in the estimation of two-person family labour supply models underlying much of the current literature. ${ }^{58} \mathrm{~A}$ key assumption is that the productivity of home child care time, $k_{h}$ (typically labelled "leisure"), is constant across all households, with $1 \mathrm{~h}$ priced at the wage. In addition, with market consumption, $x$, defined as a Hicksian composite good and selected as numeraire with price of one, the standard empirical model implicitly sets $k_{h}=1$ across all households, ${ }^{59}$ in contrast to $k_{h}=w_{2 h}$ in Model 1. Since this literature also defines bought-in child care as expenditure on the market good, we can denote expenditure on child care by $x_{b h}$ and rewrite the household's budget constraint as

$$
x_{h}+x_{b h} \leq \sum_{i=1}^{2} w_{i h} l_{i h} \quad h \in \mathcal{H}
$$

and the child care production function as

$$
z_{h}=\gamma\left[\beta c_{h}^{\rho_{h}}+(1-\beta) x_{b h}^{\rho_{h}}\right]^{1 / \rho_{h}} \quad h \in \mathcal{H}
$$

In this model variation in the price of bought-in child care across households, an exogenous variable, is necessarily interpreted as a variation in the quantity of child care, since this is measured by expenditure. ${ }^{60}$

To match the data on heterogeneity in second earner labour supply, we cannot introduce differences in preferences because we wish to make welfare comparisons. Nor can we attribute the observed heterogeneity to variation in home productivity or the price of bought-in care since the model rules out these possibilities. Moreover, as noted previously, the possible variation in $w_{2 h}$ is too narrow for this purpose, given that it must lie somewhere at or below the primary wage and above the minimum

\footnotetext{
58 For an outline of the theoretical framework of the standard household labour supply model and survey of empirical applications, see Blundell and MaCurdy (1999, Section 7).

59 The arbitrariness of this assumption was recognised by Stern (1976) who noted the potential sensitivity of estimated parameters to the assumed productivity or quality of "leisure".

60 Heckman (1974) notes that data limitations make it impossible to measure the price per unit of quality of bought-in care, and that measuring quality by expenditure with a normalised market price of unity is debatable but standard practice for want of anything better. These assumptions continue to be adopted in more recent studies, including extensions of the unitary model to collective empirical applications with child care. See, for example, Cherchye et al. (2012) and the literature cited there.
} 
Table 4 Model 2: Variation in $\rho_{\mathrm{h}}: \rho_{1}=-0.65$ and $\rho_{2}=0.3$

\begin{tabular}{lllllllll}
\hline$\pi$ & Tax system & $\tau_{1}, t_{1}$ & $\tau_{2}, t_{2}$ & $\alpha, a$ & $\mathrm{Bkt}^{\mathrm{a}}$ & $\mathrm{SW}$ & $\mathrm{H} 1 \mathrm{~h}^{\mathrm{b}}$ & $\mathrm{H} 2 \mathrm{~h}^{\mathrm{c}}$ \\
\hline 0.2 & Joint & 0.04 & 0.10 & 4575 & 97 & 57,746 & 1.73 & 7.54 \\
& Individual & 0.03 & 0.44 & 5959 & 95 & 57,988 & 1.82 & 7.68 \\
0.3 & Joint & 0.06 & 0.11 & 6589 & 97 & 147,168 & 1.59 & 7.24 \\
& Individual & 0.03 & 0.48 & 7073 & 92 & 148,373 & 1.82 & 7.68 \\
0.4 & Joint & 0.07 & 0.12 & 7582 & 97 & 515,261 & 1.52 & 7.08 \\
& Individual & 0.04 & 0.50 & 9131 & 89 & 520,947 & 1.73 & 7.54 \\
0.5 & Joint & 0.08 & 0.14 & 8554 & 97 & $2,691,453$ & 1.45 & 6.92 \\
& Individual & 0.04 & 0.52 & 9832 & 87 & $3,032,220$ & 1.73 & 7.54 \\
0.6 & Joint & 0.09 & 0.16 & 9495 & 98 & $41,897,056$ & 1.39 & 6.72 \\
& Individual & 0.05 & 0.55 & 11,089 & 87 & $42,671,180$ & 1.66 & 7.39 \\
\hline
\end{tabular}

${ }^{\mathrm{a}}$ Income percentile of bracket point; ${ }^{\mathrm{b}}$ median $\mathrm{H} 1$ second hours; ${ }^{\mathrm{c}}$ median $\mathrm{H} 2$ second hours

wage. To generate the required degree of heterogeneity, we are therefore limited to variation in the production parameter, $\rho_{h}$.

Again we construct a pre-tax benchmark population of households giving, for the same value of $\rho_{h}$ for all households, an optimal second earner labour supply at every wage pair of $5 \mathrm{~h}$ /day. We obtain this benchmark case by setting $\beta_{h}=0.5$ and $\gamma=2$ as in Model 1, and $\rho=0$ (the Cobb-Douglas case) across all households.

This benchmark case, since it again implies identical marginal value productivities for the inputs $c_{h}$ and $x_{b h}$, would look very similar to that shown in Fig. 2 earlier, but now we perturb the equilibrium by varying the determinant of the elasticity of substitution, $\rho_{h}$, as just discussed. This generates different pairs of marginal productivity curves for $\mathrm{H} 1$ and $\mathrm{H} 2$ households, which intersect at different levels of labour supplies/domestic child care. We select values of $\rho_{h}$ above and below $\rho=0$ that generate labour supplies for $\mathrm{H} 1$ and $\mathrm{H} 2$ households that match their data means. This outcome is achieved by setting $\rho_{1 h}=-0.65$ and $\rho_{2 h}=0.3$. Table 4 presents results for the optimal marginal tax rates and lump sums, bracket points and aggregate social welfare values, $\mathrm{SW}$, under piecewise linear joint and individual taxation for $\pi=0.2$ to 0.6 .

The values selected for $\rho_{1 h}$ and $\rho_{2 h}$ imply that home and bought-in care are strong complements for $\mathrm{H} 1$, whereas they tend to be substitutes for $\mathrm{H} 2$. As a consequence, household $\mathrm{H} 1$ specialises more in the use of home time in the production of $z$, the input with the lower productivity with $w_{2}>1$. H1 households therefore have a lower output of $z$ and face a higher price per unit, $p_{z}$. For example, for $\pi=0.3$, the median $p_{z}$ for $\mathrm{H} 1$ is 9.2 and 9.0, and for $\mathrm{H} 2,3.4$ and 3.3, under joint and individual taxation, respectively. Consequently, household income continues to understate the welfare of $\mathrm{H} 1$ relative to that of $\mathrm{H} 2$, as in Model 1, but to a lesser degree.

When we compare aggregate measures of SW, we find that individual taxation is again consistently superior to joint taxation, and increasingly so as we increase the degree of inequality aversion, $\pi$, from 0.2 to 0.6 . Again the rate scale under individual taxation is far more progressive than under joint taxation because a higher marginal 
rate can, in effect, be applied selectively to the incomes of top primary earners with much higher wage rates.

As in the preceding Model 1, the superiority of individual taxation is driven very strongly by a gap between the utility levels of those in the top percentiles and those in the lower and middle percentiles. In other words, together with efficiency gains, the high degree of inequality across the primary wage distribution contributes substantially to the result that individual taxation is superior to joint taxation.

\section{Conclusions}

The choice between joint and individual income as the tax base is an important one because of its implications for the efficiency and equity of the tax system. The majority of the population lives in households that have, actually or potentially, two earners, and the high degree of heterogeneity across households in the second earner's market labour supply, and therefore in the production of domestic goods and services, presents a challenge in modelling the underlying behavioural unit in the optimal taxation problem.

It is necessary to provide an empirically well-founded explanation of this heterogeneity, which at the same time clarifies the equilibrium relationship between total labour income and the achieved level of utility as we move through the population of households, since this relationship is an important determinant of the relative merits of joint and individual taxation.

A model in which this relationship is monotonic supports the intuition that a move from joint to individual taxation could have an equity cost to set against the efficiency gain from such a move. ${ }^{61}$ On the other hand, the model presented in Sect. 2 of this paper undermines the plausibility of this relationship and so weakens the argument. The model shows that the nature of the second earner's time constraint and the cost and quality of child care play a central role in explaining labour supply heterogeneity, as well as yielding the implication that household income is not a reliable indicator of a household's real living standard. Combining that with a realistic specification of the empirical wage distribution leads to the conclusion that the argument ultimately does not hold. ${ }^{62}$

It is essential to take account of the shape of the primary earner wage distribution. The degree of inequality in this, which has greatly increased over the period since Boskin and Sheshinski first presented their argument for selective taxation, determines

\footnotetext{
61 Though the numerical results presented in Boskin and Sheshinski (1983) also suggest that the net welfare gain from the policy change is still positive. Apps and Rees (1999) suggest that in the type of model used by Boskin and Sheshinski the difference between male and female elasticities has to be small for joint taxation to dominate.

62 In carrying out the numerical calculations in Sect. 4 we have used labour supply elasticities. There is a recent literature which argues that, particularly with respect to primary earners at the top of the income distribution, it is the elasticity of taxable earnings (ETI) that really matters, and this is considerably higher than the labour supply elasticities we have used. However, we are convinced by the work of Moffitt and Wilhelm (2000), Saez et al. (2012) and Piketty et al. (2014) that it is the labour supply elasticity rather than the ETI which is the relevant behavioural parameter for normative analysis of the kind carried out in this paper.
} 
the fairness with which each tax system distributes the tax burden across households. We have argued that in light of this marked inequality in the primary earner wage distribution, a move from joint to individual taxation results in both a more efficient and a fairer allocation of the aggregate tax burden. In numerical versions of the model calibrated to reflect the empirical distributions of wages and labour supplies, and given standard formulations of society's distributional preferences, we consistently find that the optimal piecewise linear tax system based on individual income yields a higher social welfare than the optimal system based on joint income.

A central result of both the theoretical and numerical analyses is the deeper understanding of the deficiencies of income-splitting from the equity point of view. These have become accentuated, not only by the growth in gross wage and income inequality, but also by the reductions in top tax rates, further increasing net income inequality, that have occurred in the past few decades. The opportunity to reduce one's tax liability that the joint taxation system offers to very high-wage earners severely constrains the extent to which the tax system can achieve an equitable allocation of the tax burden between households in the low to middle region of the distribution of well-being and households at the top. The sharp differences in the marginal rate structures of the two tax systems reflect the compositions of the subsets of individuals in the respective brackets, with second earners with high elasticities and primary earners with low elasticities being pooled under joint taxation and separated under individual taxation. Removal of the income-splitting advantage leads to high-wage primary earners being placed in the upper tax bracket regardless of the incomes of their spouses, with a consequential sharp increase in the redistributional possibilities made available by the tax system. In this way, the tax system would counteract, rather than exacerbate, the effects of the trend in inequality of pre-tax wages and incomes.

The household model we have specified is based on a "unitary" approach to the household, in which we effectively assume that the welfare weights the household attaches to the well-being of the two individuals correspond to those applied by the tax authority or "planner". ${ }^{63}$ However, we can show that the results are strengthened if we extend the model to allow the household's welfare weights to vary positively with net-of-tax wage rates, ${ }^{64}$ and assume that the weight the planner places on the utility of the second earner is at least as high as what she receives in the household. The move from joint to individual taxation in that case yields a form of "double dividend", with a gain in within-household as well as between-household equity.

Acknowledgements We are grateful to Vidar Christiansen and participants in the 2016 CESIfo Public Economics Conference, and to Kai Konrad and participants at the 2016 Tax Research Conference organised by the Max Planck Institute for Tax Law and Public Finance and the Ross Parsons Centre, The University of Sydney Law School, as well as to the two referees, for very helpful comments. We also thank Yuri

\footnotetext{
63 In Apps and Rees (1988) this is referred to as the "non-dissonance" assumption. For recent work relaxing this assumption see Meier and Rainer (2015) and Cremer et al. (2016).

64 This can, but need not, be rationalised in terms of a Nash bargaining analysis of household resource allocation. See, for example, Gugl (2009). It would result from just about any model in which the weight given to an (adult) individual's well-being in the household increases with their net-of-tax wage rate, as in the exchange model of Apps (1982) and the non-cooperative models of Konrad and Lommerud (1995, 2000), or indeed earnings, as in the game-theoretic model of Basu (2006).
} 
Andrienko for excellent research assistance. The research was supported under the Australian Research Council's Discovery Project funding scheme (Project ID: DP120104115).

Open Access This article is distributed under the terms of the Creative Commons Attribution 4.0 International License (http://creativecommons.org/licenses/by/4.0/), which permits unrestricted use, distribution, and reproduction in any medium, provided you give appropriate credit to the original author(s) and the source, provide a link to the Creative Commons license, and indicate if changes were made.

\section{Appendix A}

\section{Part 1: Comparative statics analysis of the household model}

The comparative statics effects of interest are the signs of the effects on optimal labour supply $l_{2 h}^{*}$ and quality choice $q_{h}^{*}$ of changes in the second earner wage rate $w_{2 h}$ and the productivity and price parameters $\tilde{\kappa}$ and $\tilde{\varepsilon}$, respectively. The household's problem as stated in the text is

$$
\begin{aligned}
\max _{x_{h}, l_{i h}, q_{h}} u_{h}= & x_{h}-\hat{u}_{1}\left(l_{1 h}\right)+\hat{u}_{2}\left(z\left(k_{h}\left(1-l_{2 h}\right), q_{h} l_{2 h}\right)\right) \quad h \in \mathcal{H} \\
& \text { s.t. } x_{h} \leq w_{1 h} l_{1 h}+\left[w_{2 h}-p_{h}\right] l_{2 h}
\end{aligned}
$$

where:

$$
k_{h}=k\left(w_{2 h}\right)+\kappa_{h}>0, p_{h}=p\left(q_{h}\right)+\varepsilon_{h}>0
$$

and $\kappa_{h}$ and $\varepsilon_{h}$ are the household's realisations of $\tilde{\kappa}$ and $\tilde{\varepsilon}$, respectively.

Writing the Lagrange function as

$$
\mathcal{L}_{h}=u_{h}+\lambda_{h}\left(w_{1 h} l_{1 h}+\left(w_{2 h}-p_{h}\right) l_{2 h}-x_{h}\right)
$$

the first-order conditions are

$$
\begin{aligned}
& \frac{\partial \mathcal{L}_{h}}{\partial x_{h}}=1-\lambda_{h}=0 \\
& \frac{\partial \mathcal{L}_{h}}{\partial l_{1 h}}=\hat{u}_{1}^{\prime}\left(l_{1 h}^{*}\right)-\lambda_{h} w_{1 h}=0 \\
& \frac{\partial \mathcal{L}_{h}}{\partial l_{2 h}}=\left(-\frac{\partial z}{\partial c_{h}}+\frac{\partial z}{\partial b_{h}}\right) \hat{u}_{2}^{\prime}+\lambda_{h}\left(w_{2 h}-p_{h}\right)=0 \\
& \frac{\partial \mathcal{L}_{h}}{\partial q_{h}}=\left[\hat{u}_{2}^{\prime} z_{2}-\lambda_{h} p_{h}^{\prime}\left(q_{h}^{*}\right)\right] l_{2 h}^{*}=0
\end{aligned}
$$

together with the budget constraint. The household's marginal utility of income is denoted by $\lambda_{h}$. Clearly the additive separability and quasilinearity in the utility function buy a great deal of simplicity in these conditions. The compensated labour supply function for 1 is simply $l_{1 h}^{*}\left(w_{1 h}\right) \equiv\left[\hat{u}_{1}^{\prime-1}\left(w_{1 h}\right)\right]$, and the numeraire consumption good absorbs all income effects. 
For purposes of the comparative statics analysis, it is useful to define

$$
\hat{u}_{2}\left(z\left(k_{h}\left(1-l_{2 h}\right), q_{h} l_{2 h}\right)\right) \equiv \varphi\left(l_{2 h}, q_{h}, k_{h}\right) .
$$

Moreover, from the first-order conditions it is clear that the optimal values $l_{2 h}^{*}$ and $q_{h}^{*}$ are fully determined by the two conditions ${ }^{65}$

$$
\begin{array}{r}
\varphi_{1}\left(l_{2 h}^{*}, q_{h}^{*}, k_{h}\right)+\left[w_{2 h}-\left(p\left(q_{h}^{*}\right)+\varepsilon_{h}\right)\right]=0 \\
\varphi_{2}\left(l_{2 h}^{*}, q_{h}^{*}, k_{h}\right)-p^{\prime}\left(q_{h}^{*}\right) l_{2 h}^{*}=0
\end{array}
$$

In interpreting the comparative statics results of the model, it is useful to begin by assuming that $k_{h}$, like $w_{2 h}$ and $\varepsilon_{h}$, is fixed exogenously. Standard comparative statics analysis on these conditions then gives:

\section{Proposition A1}

$$
\begin{aligned}
\frac{\partial l_{2 h}^{*}}{\partial w_{2 h}} & =\frac{-\left(\varphi_{22}-p^{\prime \prime} l_{2 h}^{*}\right)}{D}>0 ; \\
\frac{\partial q_{h}^{*}}{\partial w_{2 h}} & =\frac{\left(\varphi_{21}-p^{\prime}\right)}{D} \gtreqless 0 \\
\frac{\partial l_{2 h}^{*}}{\partial \varepsilon_{h}} & =-\frac{\partial l_{2 h}^{*}}{\partial w_{2 h}}<0 ; \frac{\partial q_{h}^{*}}{\partial \varepsilon_{h}}=-\frac{\partial q_{h}^{*}}{\partial w_{2 h}} \gtreqless 0
\end{aligned}
$$

where

$$
D \equiv \varphi_{11} \varphi_{22}-\left(\varphi_{12}\right)^{2}
$$

and $D>0$ from the second order condition.

With $k_{h}$ fixed, second earner labour supply certainly increases with the wage, since

$$
\varphi_{22}=\hat{u}_{2}^{\prime \prime}\left(z_{2} l_{2 h}^{*}\right)^{2}+\hat{u}_{2}^{\prime} z_{22} l_{2 h}^{* 2}<0
$$

This alone ensures that household income and welfare both increase with the wage. The effect of a wage increase on quality of bought-in care is however ambiguous, depending as it does on the sign of $\varphi_{21}$, which is the derivative of the marginal value product of $q_{h}\left(\mathrm{MVP}_{q}\right)$ with respect to labour supply, and is given by

$$
\varphi_{12}=\varphi_{21}=\left[\left(z_{22} q_{h}^{*}-z_{12} k_{h}\right) l_{2 h}^{*}+z_{2}\right] \hat{u}_{2}^{\prime}+z_{2} l_{2 h}^{*}\left(z_{2} q_{h}^{*}-z_{1} k_{h}\right) \hat{u}_{2}^{\prime \prime} \gtreqless 0
$$

This sign depends on whether parental and bought-in child care are Hicksian substitutes or complements, and on which of them has the higher marginal product at the equilibrium, which in turn depends on whether $w_{2 h}$ is greater or less than $p_{h}$. If the net effect of the increase in $l_{2 h}^{*}\left(=b_{h}\right)$ is to reduce $\operatorname{MVP}_{q}$, then $\varphi_{21}<0$ and the increase in $w_{2 h}$ reduces $q_{h}^{*}$, which is somewhat counterfactual. Intuitively, faced with the need

65 In the standard notation $\varphi_{1}$ denotes $\partial \varphi / \partial l_{2 h}$ and so on. 
to buy in more child care associated with the increase in labour supply induced by the higher wage rate, the household saves money on child care by reducing its quality. Though not particularly plausible, there are no a priori grounds to rule this case out. The alternative case is where the increase in $l_{2 h}^{*}$ increases $\mathrm{MVP}_{q}$ by more than enough to offset the increased price resulting from choosing a higher quality of child care, $\left(\varphi_{21}-p^{\prime}\right)>0$ and so $q_{h}^{*}$ increases.

Assuming now that $k_{h}=k\left(w_{2 h}\right)+\kappa_{h}$ we have that in general terms

$$
\begin{aligned}
\frac{\partial l_{2 h}^{*}}{\partial w_{2 h}} & =\left.\frac{\partial l_{2 h}^{*}}{\partial w_{2 h}}\right|_{k_{h}=\mathrm{const}}+\frac{\partial l_{2 h}^{*}}{\partial k_{h}} k^{\prime}\left(w_{2 h}\right) \\
\frac{\partial q_{h}^{*}}{\partial w_{2 h}} & =\left.\frac{\partial q_{h}^{*}}{\partial w_{2 h}}\right|_{k_{h}=\mathrm{const}}+\frac{\partial q_{h}^{*}}{\partial k_{h}} k^{\prime}\left(w_{2 h}\right)
\end{aligned}
$$

implying:

\section{Proposition A2}

$$
\begin{aligned}
\frac{\partial l_{2 h}^{*}}{\partial w_{2 h}} & =\frac{-\left(\varphi_{22}-p^{\prime \prime} l_{2 h}^{*}\right)-\left[\varphi_{13}\left(\varphi_{22}-p^{\prime \prime} l_{2 h}^{*}\right)-\varphi_{23}\left(\varphi_{21}-p^{\prime}\right)\right] k^{\prime}\left(w_{2 h}\right)}{D} \gtreqless 0 \\
\frac{\partial q_{h}^{*}}{\partial w_{2 h}} & =\frac{\left(\varphi_{21}-p^{\prime}\right)-\left[\varphi_{11} \varphi_{23}-\varphi_{13}\left(\varphi_{21}-p^{\prime}\right)\right] k^{\prime}\left(w_{2 h}\right)}{D} \gtreqless 0
\end{aligned}
$$

Essentially then, the ambiguity in the effect of the wage rate on labour supply comes about because we may have that $\partial l_{2 h}^{*} / \partial k_{h}<0$, or, intuitively, that an increase in the productivity of the second earner's time in child care increases the amount of time she spends on it and therefore reduces her market labour supply, other things being equal. In the case of the effect of the wage rate on bought-in quality, the addition of the term $\partial q_{h}^{*} / \partial k_{h}$ suggests the possibility of a "matching effect". If, as seems empirically plausible, increases in the second earner's productivity in child care leads the household to demand increasing quality in bought-in child care, this makes it more likely that the latter increases with the second earner's wage as a measure of her human capital.

In these expressions, we have:

$$
\begin{aligned}
\varphi_{11}= & \left(z_{11} k_{h}^{2}-2 z_{12} k_{h} q_{h}^{*}+z_{22} q_{h}^{* 2}\right) \hat{u}_{2}^{\prime}+\left(z_{2} q_{h}^{*}-z_{1} k_{h}\right)^{2} \hat{u}_{2}^{\prime \prime}<0 \\
\varphi_{13}= & \varphi_{31}=\left[z_{12}\left(1-l_{2 h}^{*}\right) q_{h}^{*}-z_{11}\left(1-l_{2 h}^{*}\right) k_{h}-z_{1}\right] \hat{u}_{2}^{\prime} \\
& +z_{1}\left(1-l_{2 h}^{*}\right)\left(z_{2} q_{h}^{*}-z_{1} k_{h}\right) \hat{u}_{2}^{\prime \prime} \gtreqless 0 \\
\varphi_{23}= & \varphi_{32}=z_{1} z_{2}\left(1-l_{2 h}^{*}\right) l_{2 h}^{*} \hat{u}_{2}^{\prime \prime}+z_{12} l_{2 h}^{*}\left(1-l_{2 h}^{*}\right) \hat{u}_{2}^{\prime} \gtreqless 0
\end{aligned}
$$




\section{Part 2: Household equilibrium and indirect utilities for the taxation analysis}

To present the results of the analysis ${ }^{66}$ in the most useful way for purposes of the tax analysis it is useful to reformulate the household model as follows. We rewrite the utility functions as

$$
\hat{u}_{1}\left(l_{1 h}\right) \equiv \hat{u}_{1}\left(y_{1 h} / w_{1 h}\right) \equiv \psi_{1 h}\left(y_{1 h} ; w_{1 h}\right)
$$

and

$$
\hat{u}_{2}\left[z\left(k_{h} c_{h}, q_{h} b_{h}\right)\right] \equiv \hat{u}_{2}\left[z\left(k_{h}\left(1-y_{2 h} / w_{2 h}\right), q_{h} y_{2 h} / w_{2 h}\right)\right] \equiv-\psi_{2 h}\left(y_{2 h} ; w_{2 h}\right)
$$

where the $\psi_{i h}(\cdot)$ are strictly increasing and convex in $y_{i h}$. We retain the assumption of identical preferences $\hat{u}_{1}(\cdot), \hat{u}_{2 h}(\cdot)$ across households, as is usual in optimal tax analysis. $^{67}$

\section{Joint taxation}

A household $h \in \mathcal{H}$ solves the problem

$$
\max _{x_{h}, y_{i h}} u_{h}=x_{h}-\sum_{i=1}^{2} \psi_{i}\left(y_{i h} ; w_{i h}\right)
$$

subject to a budget constraint determined by the tax system. We consider three cases which provide the results we require, the partial derivatives of the household's indirect utility function with respect to the tax parameters. We write below the constraints for each of these cases together with these derivatives.

Case 1. The household is at the optimum in the interior of the lower tax bracket. It therefore faces the budget constraint:

$$
x_{h}=\alpha+\left(1-\tau_{1}\right) \sum_{i} y_{i h}
$$

and the first-order conditions imply :

$$
\frac{\partial \psi_{i}}{\partial y_{i h}}=1-\tau_{1} i=1,2,
$$

\footnotetext{
66 Throughout this analysis we assume for simplicity that productivities $k$ and $q$ are determined by the wage type of the household as expressed by the gross wage rate $w_{2 h}$ rather than by the net-of-tax wage.

67 In contrast to this, empirical applications of the standard household model rely on a high degree of preference heterogeneity, expressed in terms of "preference errors", to explain the data. The problem with this is that welfare comparisons across households then become problematic and controversial. This is avoided by having prices and productivities of child care as well as wages be the drivers of across household heterogeneity in labour supplies, since these determine the feasible set rather than preferences.
} 
giving the earnings supply functions $y_{i h}\left(\tau_{1}\right)$. The properties of the functions $\psi_{i h}(\cdot)$ imply

$$
\frac{\partial y_{i h}\left(\tau_{1}\right)}{\partial \tau_{1}}<0, i=1,2,
$$

where, note, this is a compensated derivative.

We write the household indirect utility function ${ }^{68}$ as $v_{h}\left(\alpha, \tau_{1}\right)$, with, by the Envelope Theorem,

$$
\frac{\partial v_{h}}{\partial \alpha}=1 ; \frac{\partial v_{h}}{\partial \tau_{1}}=-y_{h}^{*}=-\sum_{i} y_{i h}\left(\tau_{1}\right) i=1,2,
$$

Case 2. The household is effectively constrained at the bracket limit $\eta$, in the sense that it chooses $y_{h}=\eta$, but would prefer to increase its labour supply and earnings if it would be taxed at the rate $\tau_{1}$, but not if it would be taxed at the rate $\tau_{2}$. We formulate its allocation problem by adding the constraint $y_{h} \leq \eta$, noting that this will be binding at the optimum. ${ }^{69}$ We can write the first-order conditions as

$$
\begin{aligned}
& \left(1-\tau_{1}\right)-\frac{\partial \psi_{i h}}{\partial y_{i h}}-\mu_{h}=0 i=1,2, \\
y_{h} \leq \eta \mu_{h} \geq 0 \mu_{h}\left[y_{h}-\eta\right] & =0
\end{aligned}
$$

where $\mu_{h}$ is the multiplier associated with the constraint $y_{h} \leq \eta$.

We write the indirect utility function as $v_{h}\left(\alpha, \tau_{1}, \eta\right)$, with, by the Envelope Theorem,

$$
\frac{\partial v_{h}}{\partial \alpha}=1 ; \quad \frac{\partial v_{h}}{\partial \tau_{1}}=-\eta ; \quad \frac{\partial v_{h}}{\partial \eta}=\left(1-\tau_{1}\right)-\frac{\partial \psi_{i}}{\partial y_{i h}} \geq 0
$$

Intuitively, the idea of the expression for $\partial v_{h} / \partial \eta$ is that a small relaxation of the constraint would increase consumption and utility at the rate $\left(1-\tau_{1}\right)$, which exceeds for almost every individual the marginal cost of effort $\partial \psi_{i h} / \partial y_{i h}$. In diagrammatic terms, the household is at the kink in its budget constraint at the bracket limit $\eta$. The term is zero only if $i$ 's marginal rate of substitution happens to equal $\left(1-\tau_{1}\right)$ at the kink. Note that condition (68) implies that the individuals' marginal effort costs are equalised also in this type of equilibrium. Given that the household wants to earn the income $\eta$, it allocates labour supplies so as to minimise the total utility costs of achieving this.

Case 3. The household is in equilibrium in the interior of the upper income bracket. We therefore replace the previous budget constraint by

$$
x_{h} \leq \alpha+\left(1-\tau_{2}\right) y_{h}+\left(\tau_{2}-\tau_{1}\right) \eta
$$

\footnotetext{
68 Where no confusion should arise we simplify notation by suppressing the type arguments $w_{i h}$ in the indirect utility functions.

69 Case 1 can be thought of as the case in which this constraint is non-binding.
} 
and the first-order conditions imply

$$
\frac{\partial \psi_{i h}}{\partial y_{i h}}=1-\tau_{2} \quad i=1,2,
$$

giving the earnings supply functions $y_{i h}\left(\tau_{2}\right)$. The properties of the functions $\psi_{i h}(\cdot)$ imply

$$
\frac{\partial y_{i h}\left(\tau_{2}, w_{i h}\right)}{\partial \tau_{2}}<0, \quad \frac{\partial y_{i h}\left(\tau_{2}, w_{i h}\right)}{\partial w_{i h}}>0 \quad i=1,2,
$$

Writing the indirect utility function as $v_{h}\left(\alpha, \tau_{1}, \tau_{2}, \eta\right)$ we now obtain

$$
\frac{\partial v_{h}}{\partial \alpha}=1 ; \frac{\partial v_{h}}{\partial \tau_{1}}=-\eta ; \quad \frac{\partial v_{h}}{\partial \tau_{2}}=-\left(y_{h}^{*}-\eta\right) ; \quad \frac{\partial v_{h}}{\partial \eta}=\tau_{2}-\tau_{1}>0
$$

In all three cases, it follows from the properties of the function $\psi_{i h}(\cdot)$ that $\partial v_{h} / \partial w_{i h}>$ $0, i=1,2, h \in \mathcal{H}$.

We can show that under joint taxation the household can be treated as if it were a single individual. To see this, note that we can solve the household's problem in two steps. First solve $\min _{y_{i h}} \sum_{i} \psi_{i}\left(y_{i h}, w_{i h}\right)$ subject to $\sum_{i} y_{i h} \leq y_{h}$ for any given $y_{h}$, and define $\psi_{h}\left(y_{h}\right)$ as the value function of this problem. Then, solve $\max _{x_{h} y_{h}} x_{h}-\psi_{h}\left(y_{h}\right)$ subject to the relevant budget constraint in each case.

Individual taxation With individual income as the tax base, and given that (by definition) the second earner's income is always below that of the primary earner, we can define six possible cases for the household equilibrium. In each case, we present the earnings and indirect utility functions and partial derivatives of the latter with respect to the tax instruments.

Case $1 y_{i h}^{*}<y, i=1,2$. In this case the household's budget constraint, earnings and indirect utility functions are identical to those in Case 1 of joint taxation.

Case $2 y_{2 h}^{*}<y=y_{1 h}^{*}$. The results here are derived by imposing the constraint $y_{1 h} \leq y$ on the problem and noting that it is binding at the optimum. Thus, we have $y_{2 h}^{*}=y_{2 h}\left(t_{1}, w_{2 h}\right)$, and $v_{h}\left(a, t_{1}, y\right)$, with

$$
\frac{\partial v_{h}}{\partial a}=1 ; \quad \frac{\partial v_{h}}{\partial t_{1}}=-\left(y+y_{2 h}^{*}\right) ; \quad \frac{\partial v_{h}}{\partial y}=\left(1-t_{1}\right)-\frac{\partial \psi_{1}}{\partial y_{1 h}}
$$

Case $3 y_{i h}^{*}=y, i=1,2$. Here we impose the two constraints $y_{i h} \leq y$ and take them as both binding at the optimum, giving $v_{h}\left(a, t_{1}, y\right)$ and

$$
\frac{\partial v_{h}}{\partial a}=1 ; \quad \frac{\partial v_{h}}{\partial t_{1}}=-2 y ; \quad \frac{\partial v_{h}}{\partial y}=2\left(1-t_{1}\right)-\sum_{i} \frac{\partial \psi_{i}}{\partial y_{i h}}
$$

Case $4 y_{2 h}^{*}<y<y_{1 h}^{*}$. In this case, the budget constraint becomes

$$
x_{h} \leq a+\left(t_{2}-t_{1}\right) y+\left(1-t_{2}\right) y_{1 h}+\left(1-t_{1}\right) y_{2 h}
$$


and we have $y_{1 h}^{*}=y_{1 h}\left(t_{2}, w_{1 h}\right), y_{2 h}^{*}=y_{2 h}\left(t_{1}, w_{2 h}\right)$ and the indirect utility function $v_{h}\left(a, t_{1}, t_{2}, y\right)$ with

$$
\frac{\partial v_{h}}{\partial a}=1 ; \quad \frac{\partial v_{h}}{\partial t_{1}}=-\left(y+y_{2 h}^{*}\right) ; \quad \frac{\partial v_{h}}{\partial t_{2}}-\left(y_{1 h}^{*}-y\right) ; \quad \frac{\partial v_{h}}{\partial y}=t_{2}-t_{1}
$$

Case $5 y_{2 h}^{*}=y<y_{1 h}^{*}$. We now have $y_{1 h}^{*}=y_{1 h}\left(t_{2}, w_{1 h}\right)$ and the indirect utility function $v_{h}\left(a, t_{1}, t_{2}, y\right)$ with

$$
\frac{\partial v_{h}}{\partial a}=1 ; \quad \frac{\partial v_{h}}{\partial t_{1}}=-2 y ; \quad \frac{\partial v_{h}}{\partial t_{2}}-\left(y_{1 h}^{*}-y\right) ; \quad \frac{\partial v_{h}}{\partial y}=t_{2}-t_{1}+\left(1-t_{1}\right)-\frac{\partial \psi}{\partial y_{2 h}}
$$

Case $6 y_{i h}^{*}>y, i=1,2$. This gives $y_{i h}^{*}=y_{i h}\left(t_{2}, w_{i h}\right), i=1,2$, and $v_{h}\left(a, t_{1}, t_{2}, y\right)$ with

$$
\frac{\partial v_{h}}{\partial a}=1 ; \quad \frac{\partial v_{h}}{\partial t_{1}}=-2 y ; \quad \frac{\partial v_{h}}{\partial t_{2}}-\sum_{i}\left(y_{i h}^{*}-y\right) ; \quad \frac{\partial v_{h}}{\partial y}=2\left(t_{2}-t_{1}\right)
$$

These results then feed directly into the specification of the optimal tax conditions presented in the paper.

\section{References}

Alesina, A., Ichino, A., \& Karabarbounis, L. (2011). Gender based taxation and the division of family chores. American Economic Journal: Economic Policy, 3(2), 1-40.

Almond, D., \& Currie, J. (2011). Human capital development before age five. In O. Ashenfelter, \& D. Card (Eds.), Handbook of labor economics, Vol 4b, Ch. 5 (pp. 1315-1686). Amsterdam: Elsevier.

Andrienko, Y., Apps, P., \& Rees, R. (2016). Optimal taxation and top incomes. International Tax and Public Finance, 23(6), 981-1003.

Apps, P. (1982). Institutional inequality and tax incidence. Journal of Public Economics, 18(2), $217-242$.

Apps, P., Long, N. V., \& Rees, R. (2014). Optimal piecewise linear income taxation. Journal of Public Economic Theory, 16(4), 523-545.

Apps, P., \& Rees, R. (1988). Taxation and the household. Journal of Public Economics, 35(3), 355-369.

Apps, P., \& Rees, R. (1999). On the taxation of trade within and between households. Journal of Public Economics, 73(2), 241-263.

Apps, P., \& Rees, R. (2004). Fertility, female labour supply and public policy. Scandinavian Journal of Economics, 106(4), 745-763.

Apps, P., \& Rees, R. (2009). Public economics and the household. Cambridge: Cambridge University Press. Atkinson, A. (2015). Inequality: What can be done. Cambridge, MA: Harvard University Press.

Atkinson, A., Piketty, T., \& Saez, E. (2011). Top incomes in the long run of history. Journal of Economic Literature, 49(1), 3-71.

Australian Bureau of Statistics. (2012). Household expenditure survey and survey of income and housing, Australia 2009-2010. Australian Bureau of Statistics-MiCRO. http://www.abs.gov.au/websitedbs/ D3310114.nsf/home/Microdata.

Basu, K. (2006). Gender and say: A model of household behaviour with endogenously determined balance of power. The Economic Journal, 116, 558-580.

Björklund, A., Lindahl, M., \& Plug, E. (2006). The origins of intertemporal associations: Lessons from Swedish adoption data. Quarterly Journal of Economics, 121(3), 999-1028.

Black, S., \& Devereux, P. (2011). Recent developments in intergenerational mobility. In O. Ashenfelter \& D. Card (Eds.), Handbook of labor economics (Vol. 4b, pp. 1487-1541). Amsterdam: Elsevier.

Black, S., Devereux, P., \& Salvanes, K. (2005). Why the apple doesn't fall far: Understanding intergenerational transmission of human capital. American Economic Review, 95(1), 437-449. 
Blundell, R., \& MaCurdy, T. (1999). Labor supply: A review of alternative approaches. In O. Ashenfelter \& D. Card (Eds.), Handbook of labor economics (Vol. 3, pp. 1559-1695). Amsterdam: Elsevier.

Boskin, M. (1975). Efficiency aspects of the differentiated tax treatment of market and household activity. Journal of Public Economics, 4(1), 1-25.

Boskin, M., \& Sheshinski, E. (1983). Optimal tax treatment of the family: Married couples. Journal of Public Economics, 20(3), 281-297.

Brett, C. (2007). Optimal nonlinear taxes for families. International Tax and Public Finance, 14, $225-261$.

Cherchye, L., De Roch, B., \& Vermeulen, F. (2012). Married with children: A collective labor supply model with detailed time use and intrahousehold expenditure information. American Economic Review, 102(7), 3377-3405.

Chetty, R. (2009). Sufficient statistics for welfare analysis: A bridge between structural and reduced-form methods. Annual Review of Economics, 1, 451-488.

Cremer, H., Lochazmeur, J.-M., Maldonado, D., \& Roeder, K. (2016). Household bargaining and the design of couples' income taxation. European Economic Review, 89, 454-470.

Currie, J., \& Moretti, E. (2003). Mother's education and the intergenerational transmission of human capital: Evidence from college openings. Quarterly Journal of Economics, 118(4), 1495-1532.

Dahlby, B. (1998). Progressive taxation and the marginal social cost of public funds. Journal of Public Economics, 67(1), 105-122.

Dahlby, B. (2008). The marginal cost of public funds. Cambridge, MA: MIT Press.

Dahl, G., \& Lochner, L. (2012). The impact of family income on child achievement: Evidence from changes in the EITC. American Economic Review, 102(5), 1927-1956.

Fehr, H., \& Ujhelyiova, D. (2012). Fertility, female labour supply and family policy. German Economic Review, 14(2), 138-165.

Gugl, E. (2009). Income splitting, specialization and intrafamily distribution. Canadian Journal of Economics, 42(3), 1050-1071.

Heckman, J., \& Killingsworth, M. (1986). Female labor supply: A survey. In O. Ashenfelter, \& R. Layard (Eds.), Handbook of labor economics (Vol. 1, pp. 103-204). Amsterdam and New York: North Holland.

Heckman, J. (1974). Effects of child care programs on women's work effort. Journal of Political Economy, 82(2), S236-S263.

Holmlund, H., Lindahl, M., \& Plug, E. (2001). The causal effect of parents' schooling on children's schooling: A comparison of estimation methods. Journal of Economic Literature, 49(3), 615-651.

Kleven, H., Kreiner, C., \& Saez, E. (2009). The optimal income taxation of couples. Econometrica, 77(2), 537-560.

Konrad, K., \& Lommerud, K. (1995). Family policy with non-cooperative families. Scandinavian Journal of Economics, 97, 581-601.

Konrad, K., \& Lommerud, K. (2000). The bargaining family revisited. Canadian Journal of Economics, $33(2), 471-487$.

LaLumia, S. (2008). The effects of joint taxation of married couples on labor supply and non-wage income. Journal of Public Economics, 92(7), 1698-1791.

Löken, K., Mogstad, M., \& Wiswall, M. (2012). What linear estimators miss: The effects of family income on child outcomes. American Economic Journal: Applied Economics, 4(2), 1-35.

Lundberg, S., Pollak, P., \& Stearns, J. (2016). Family inequality: Diverging patterns in marriage, cohabitation and childbearing. Journal of Economic Perspectives, 30(2), 79-102.

Lundborg, P., Nilsson, A., \& Rooth, D.-O. (2014). Parental education and offspring outcomes: Evidence from the Swedish compulsory schooling reform. American Economic Journal: Applied Economics, 6(1), 253-278.

McClelland, R., Mok, S., \& Pierce, K. (2014). Labor force participation elasticities of women as secondary earners within married couples. WP 2014-06, Congressional Budget Office, Washington, DC.

Meier, V., \& Rainer, H. (2015). Pigou meets Ramsey: Gender-based taxation with non-cooperative couples. European Economic Review, 77, 28-46.

Milligan, K., \& Stabile, M. (2011). Do child tax benefits affect the well-being of children? Evidence from Canadian child benefit expansions. American Economic Journal: Economic Policy, 3(3), 175-205.

Mirrlees, J. (1971). An exploration in the theory of optimum income taxation. Review of Economic Studies, 38, 175-208.

Moffitt, R., \& Wilhelm, M. (2000). Taxation and the labor supply decisions of the affluent. In J. Slemrod (Ed.), Does Atlas Shrug? The economic consequences of taxing the rich (pp. 193-234). New York: Russell Sage Foundation; Cambridge and London: Harvard University Press. 
Peter, K., Buttrick, S., \& Duncan, D. (2010). Global reform of personal income taxation, 1981-2005: Evidence from 189 countries. National Tax Journal, 63(3), 447-478.

Piketty, T., \& Saez, E. (2003). Income inequality in the United States, 1913-1998. Quarterly Journal of Economics, 118(1), 1-39.

Piketty, T., Saez, E., \& Stantcheva, S. (2014). Optimal taxation of top labor incomes: A tale of three elasticities. American Economic Journal: Economic Policy, 6(1), 230-271.

Rosen, H. (1977). Is it time to abandon joint filing? National Tax Journal, 30(4), 423-428.

Saez, E., Slemrod, J., \& Giertz, S. (2012). The elasticity of taxable income with respect to marginal tax rates: A critical review. Journal of Economic Literature, 50(1), 3-50.

Sandmo, A. (1990). Tax distortions and household production. Oxford Economic Papers, 42, 78-90.

Schroyen, F. (2003). Redistributive taxation and the household: The case of individual filings. Journal of Public Economics, 87, 2527-2547.

Sheshinski, E. (1972). The optimal linear income tax. Review of Economic Studies, 39, 297-302.

Sheshinski, E. (1989). Note on the shape of the optimum income tax schedule. Journal of Public Economics, 40(2), 201-215.

Slemrod, J., Yitzhaki, S., Mayshar, J., \& Lundholm, M. (1994). The optimal two-bracket linear income tax. Journal of Public Economics, 53(2), 269-290.

Steiner, V., \& Wrohlich, K. (2004). Household taxation, income splitting and labor supply incentive: A microsimulation study for Germany. CESifo Economic Studies, 50, 541-568.

Steiner, V., \& Wrohlich, K. (2008). Introducing family tax splitting in Germany: How would it affect the income distribution, work incentives, and household welfare? FinanzArchiv, 64(1), 115-142.

Stern, N. (1976). On the specification of optimum income taxation. Journal of Public Economics, 6(1-2), $123-162$.

Tuomala, M. (1984). On the optimal income taxation: Some further numerical results. Journal of Public Economics, 23(3), 351-366. 